\title{
Habitar y representar la agrociudad. Caracterización y semiótica de un espacio conflictivo: Arcos de la Frontera (Cádiz) en el primer tercio del siglo $\mathrm{XX}$
}

\author{
Inhabiting and recreating the agrotown. Description and semiotics of a \\ controversial space: Arcos de la Frontera (Cádiz) in the first third of the \\ 20th century
}

\author{
Antonio ORTEGa CASTILLO \\ Universidad de Cádiz
}

\begin{abstract}
RESUMEN
En la disciplina histórica, el estudio de un tipo de poblamiento en el que confluyen características urbanas y agrarias ha estado relegado a un segundo plano, tras la dicotomía espacio urbano-rural. En este sentido, aplicar, analizar y testar el concepto de agrociudad en un caso concreto nos puede ayudar a comprender la existencia de espacios en los que se liman las diferencias entre estos dos universos, generalmente presentados como antagónicos antes de la llegada de la era digital. Proyectando una visión micro y analizando el caso de Arcos de la Frontera (Cádiz) en el primer tercio del siglo XX, ahondamos en este paradigma al presentar las tensiones sobrevenidas en un espacio urbano y rural a la vez, la dependencia y las responsabilidades conflictivas con otras localidades, su sociabilidad formal e informal, las distintas formas de habitar y representar el espacio y sus conflictos. Planteamos una descripción del paisaje de la agrociudad y la relación de este como espacio semiótico prestando atención a la conciencia de un ethos urbano en el comportamiento de sus habitantes.
\end{abstract}

PALABRAs CLAVE

Agrociudad; Espacio semiótico; Ethos urbano; Arcos de la Frontera; Conflictividad.

\begin{abstract}
In the discipline of history, the study of settlements where urban and rural characteristics converge has been consigned to second place, behind the urban-rural dichotomy. Within this context, the application, analysis and testing of the concept of agrotown in a particular case can help us understand the existence of places where the differences between these two universes, normally portrayed as being in opposition prior to the coming of the digital era, were smoothed over. Taking a micro view and analysing the case of Arcos de la Frontera (Cádiz) in the first third of the $20^{\text {th }}$ century, allows us to examine this paradigm, presenting the tensions that arose in a space that was both urban and rural at the same time, its dependence on and responsibilities towards nearby towns that led to problems, its formal and informal social relationships, the different ways of living in and presenting the place and its conflicts. We propose a description of the setting of the rural town and the relationship of this with an interpretation of it as a semiotic space, focusing on the awareness of an urban ethos in its inhabitants' behaviour.
\end{abstract}

\section{KEYWORDS}

Agrotown; Semiotic space; Urban ethos; Arcos de la Frontera; Controversy. 
ORTEGA 
El poblamiento humano y la organización del espacio han sido uno de los temas preferentes de las Ciencias Sociales. Un análisis simplista de la ocupación del territorio distingue los asentamientos en espacio urbano y espacio rural, acentuando las diferencias entre ambos. Es conocido que la realidad es mucho más compleja, ya que existen lugares y comunidades que comparten rasgos urbanos y rurales como elementos indisolubles. Desde la Geografía, la Antropología o la Sociología se han estudiado las condiciones concretas de poblaciones que constituyen lugares de transición, como la agrociudad, que en el caso andaluz toman especial importancia ${ }^{1}$. El concepto de agrociudad comprende a aquellas poblaciones resultado de un híbrido entre condiciones y rasgos peculiares de urbanidad y a la vez fuertemente impregnadas por las actividades económicas agrícolas y el mundo rural en general ${ }^{2}$. Estos espacios no se dan solo en España, sino que podemos encontrarlos en otras partes del mundo, como las zonas meridionales de los países mediterráneos y el continente americano ${ }^{3}$.

A lo largo de los años estos espacios de transición han sido denominados como ciudad-pueblo, aldea-ciudad o pueblo grande. Se trata de conceptos antiguos en el estudio de la geografía urbana, siendo el de agrociudad el más reconocido y el que ha pervivido. Convendría, así, definir qué son las agrociudades y qué jerarquía, disposición, tamaño o perfil funcional desempeñan en el territorio. Últimamente, el geógrafo Luis Miguel Sánchez ha respondido convenientemente a estas cuestiones. Las agrociudades son:

Grandes pueblos, centros estratégicos en la organización del espacio al margen de las grandes capitales provinciales, de grandes hechuras y dimensiones urbanas, incluyendo a veces un plano ordenado -con procesos históricos asimilables a los de ensanche-, y que se erigían además de forma estable a lo largo del tiempo como centros del poder local y subprovincial. Estos núcleos contaban de forma habitual, entre otros servicios y equipamientos, con juzgado, escuelas, pósito, ayuntamiento, y eran la sede habitual de la burguesía empresarial y la aristocracia terrateniente de cada comarca. Sin embargo, estos centros de poder territorial vivían al margen de cualquier desarrollo industrial

1. Para la teoría y definición de las agrociudades andaluzas, Antonio LÓPEZ OnTIVEROS, "La agrociudad andaluza: caracterización, estructura y problemática”, Estudios Regionales, 39 (1994), pp. 59-91; Francisco LÓPEZ-CASERO OLMEDO, "Identidad, estructura social y desarrollo local. Redefinición del pueblo, con referencia especial a las agrociudades”, Apuntes y documentos para una historia de Osuna, 1 (1996), pp. 3-4.

2. Es importante resaltar una diferenciación entre espacio rural y espacio agrícola: el segundo se referiría a la producción y a la actividad de la tierra además de a su propiedad mientras el espacio rural abarcaría la "relación con el campo en general" comprendiendo las relaciones con el paisaje, el medio ambiente y la naturaleza (LÓPEZ-CASERO, "Identidad, estructura social y desarrollo local”, pp. 3-4).

3. Algunos trabajos son: Francisco LóPEZ-CASERo OLMEDo, "Las agrociudades en Córdoba”, Demófilo, 36 (2000), pp. 33-56; José Manuel NAVARRo DomíngUEZ, "Estructura urbana y uso de espacio en una agrociudad andaluza. Carmona en el tránsito del Antiguo al Nuevo Régimen”, Carel, 4 (2006) pp. 1.7711.805; José Antonio Nieto CALAMAESTRA, "La agrociudad andaluza: aproximación a su complejidad sociodemográfica a través del caso de Alcalá la Real (Jaén)”, Magina, 9 (2001), pp. 169-182; José Luis ANTA FÉLEZ, "La agrociudad: un modelo para acercarse a Jaén”, en José Miguel DELGADO BARRADO y Amparo LóPEZ ARANDIA (coords.), Ciudades de Jaén en la historia (siglos XV-XXI): mitos y realidades, Sevilla, Universidad de Sevilla, 2011; Salvador RodRíGUEz BECERRA, "Las agrociudades en Andalucía", IX Jornadas de Etnología de Andalucía, Úbeda, 1999. También se ha adaptado este concepto en América Latina en Mario CERUTTI, "La construcción de un agrociudad en el noroeste de México. Ciudad Obregón (1925-1960)”, Secuencia, 64 (2006), pp. 113-143 (https://doi.org/10.18234/secuencia.v0i64.954). La visión de la agrociudad italiana es deudora del trabajo de Rolf MonHEIM, publicado en alemán por primera vez en Geographische Zeitschrift, 59 (1971), pp. 204-255, y más tarde en el estudio coordinado por Francisco LóPEZ-CASERO OLMEDO, La agrociudad mediterránea. Estructuras sociales y procesos de desarrollo, Madrid, Ministerio de Agricultura, Pesca y Alimentación, 1989. 
moderno capaz de transformar su estructura socioeconómica secular y no eran más que enormes concentraciones de población estancadas en su peculiar estructura urbana, absolutamente dependientes del medio agrario que les rodeaba ${ }^{4}$.

Uno de los estudios más influyentes a la hora de categorizar la agrociudad y catalogar sus rasgos ha sido el de Francisco López Ontiveros. En él, y para el caso andaluz, destacó que ésta posee un volumen poblacional aproximado entre $3.000 \mathrm{y}$ 30.000 habitantes que se concentran mayoritariamente en un punto concreto y tienen un extenso término municipal con feraces campos. Sus actividades económicas fundamentalmente son agrícolas y ganaderas, pero poseen un comercio y una industria que cubren las necesidades de sus habitantes. Su importancia en el territorio está ligada a la existencia de un patrimonio histórico-artístico asociado a su pasado y sus moradores son portadores de unos rasgos y modos de vida que conforman una identidad urbana y un comportamiento localista. Esto es lo que se conoce como ethos urbano ${ }^{5}$. A estos caracteres podemos añadir, como bien señaló el antropólogo Andrés Barrera González, una serie de peculiaridades en relación a perfiles socioculturales que destacan una "especificidad sociológica", los cuales serían: importantes desigualdades entre los grupos sociales, una "marcada disociación y antagonismo clasista”, una "morfología urbanística compacta, intensas pautas de sociabilidad informal, fuertes sentimientos de identificación localista, predominio de un ethos urbano en detrimento de los valores y signos de identidad asociados al mundo rural” ${ }^{\text {. }}$

En los últimos años, la Historia Urbana ha destacado cómo en el proceso modernizador, que no fue lineal ni unidireccional, estos espacios intermedios desempeñaron un papel importante y tuvieron, además, un comportamiento particular, en función de las diversas realidades locales ${ }^{7}$. No obstante, el concepto de la agrociudad no ha arraigado lo necesario como para convertirse en objeto de estudio principal de la Historia. Se le ha otorgado un lugar marginal en las investigaciones, en el contexto de una Historia estrictamente sociopolítica o económica que se ha limitado a adscribir ciertos espacios a este paradigma, en relación, por lo general, a una dependencia del modelo productivo o, como mucho, socioprofesional, pasando desapercibidos otros aspectos. La Antropología, la Sociología y la Geografía han demostrado que el concepto es más amplio, puesto que abarca lo que se ha convenido en denominar ethos urbano: un conjunto de actitudes y comportamientos de los habitantes de estos lugares que se distinguen del mundo rural por sus rasgos de urbanidad ${ }^{8}$. Sin

4. Luis Miguel SÁNCHEz Escolano, “Ciudades medias y articulación espacial en el litoral mediterráneo andaluz (1950-2014). Nuevas tipologías urbanas para el diagnóstico y el desarrollo territorial”, tesis doctoral Universidad de Granada, 2016, pp. 130-141.

5. LÓPEZ-CASERO, “La agrociudad”.

6. Andrés BARrera GonZÁlez, "Perspectivas antropológicas en el estudio de la agrociudad: el caso de Puente Genil”, en López-CASERO, La agrociudad mediterránea, pp. 87-110.

7. Santiago DíEz CANO, “¿Ciudad levítica o ciudad diferente? En torno a la historia urbana de la España interior”, Historia Social, 22 (1996), pp. 63-77; Luis Enrique OTERo CARVAJAL, "El Madrid moderno, capital de una España urbana en transformación, 1860-1931”, Historia Contemporánea, 39 (2010), pp. 541-588.

8. Desde la Antropología y la Sociología, los trabajos ya comentados de LóPEz-CASERo; desde la Geografía: Damián MACÍAs Rodríguez, María Teresa PÉREz CANO y Blanca DEL EsPino HidALGO, “Las agrociudades andaluzas en el patrimonio agrario: la campiña de Estepa y Puente Genil”, en Ángel Raúl Ruiz Pulpón, Manuel Antonio Serrano de la Cruz SAntos-Olmo y Julio Plaza Tabasco (eds.), Treinta años de Política Agraria Común en España. Agricultura y multifuncionalidad en el contexto de la nueva ruralidad, Ciudad Real, Asociación de Geógrafos Españoles, 2016, pp. 767-781. En relación a la adscripción de algunas poblaciones como agrociudad en investigaciones de Historia que 
embargo, este ethos urbano, y más que eso, la concepción, el significado o la semántica de "la ruralía y la urbanitas” derivan de la perspectiva de grupo. Por lo tanto, habría que tener en cuenta esta representación, que es subjetiva y otorga un significado al espacio y a los comportamientos sociales que se dan en él, lo cual influye, por ende, en las conductas de sus habitantes ${ }^{9}$. Estas dinámicas particulares en la frontera de la urbanización adoptarán diferentes modelos de comportamiento, que influirán de formas distintas en el proceso modernizador, como ha destacado en la Historia, para el caso gallego, Isidro Dubert ${ }^{10}$.

En este sentido, las propuestas de enfoques como el del estudio espacial nos ofrecen perspectivas enriquecedoras para tratar la semiótica de los espacios y establecer puntos de relación entre la Historia, la Sociología, la Geografía, la Filosofía Social y la Antropología ${ }^{11}$. Es por ello que, sin perjuicio de la visión tradicional de la agrociudad, dependiente de la mirada productiva, creemos necesario prestar atención al espacio sociogeográfico, que posee dos vertientes: la objetual y la cosmológica ${ }^{12}$. Entendiendo que el espacio sociogeográfico es concedido por el valor que le confiere la sociedad, pensamos que es un recurso interesante para comprender el funcionamiento de la estigmatización social en los barrios populares y plantear la conflictividad en la agrociudad $^{13}$.

Así, y porque creemos que la realidad de Arcos de la Frontera en el primer tercio del siglo XX responde perfectamente al perfil de la agrociudad, sumamente importante en la España de entonces, hemos dividido el artículo en dos grandes apartados. En el primero, descriptivo y analítico, abordamos brevemente la caracterización del objeto de estudio espacial dentro del paradigma de agrociudad. Es decir, identificamos a Arcos como espacio productivo, morfológico y objetual. En un

tienen otros objetos de estudio principales, citamos tres ejemplos contextualizados en el primer tercio del siglo XX, del que trata este artículo: el trabajo de Diego CARO CANCELA sobre Jerez, donde se realiza un estudio socioprofesional: Violencia política y luchas sociales: la Segunda República en Jerez de la Frontera (1931-1936), Jerez, Ayuntamiento de Jerez, 2001; sobre la misma ciudad, Enrique MonTAÑÉS PRIMICIA, Transformación agrícola y conflictividad campesina en Jerez de la Frontera (1880-1923), Cádiz, Ayuntamiento de Jerez, 1997; otro estudio político en una agrociudad, Fernando DEL REY REguillo, Paisanos en lucha. Exclusión política y violencia en la Segunda República española, Madrid, Biblioteca Nueva, 2008.

9. Una idea tratada en el estudio de José Antonio FERNÁNDEZ DE ROTA Y MONTER para el caso del caserío gallego, donde se señala que "las connotaciones valorativas de estos términos [rural-urbano] toman distintas tonalidades semánticas según los diversos puntos de vista” ("Mundo rural y mundo urbano en una villa gallega”, en LÓPEZ-CASERO, La agrociudad mediterránea, pp. 359-398).

10. Isidro DUBERT, “Transformación urbana y modernidad en las ciudades y villas de Galicia, 18601930” en Luis Enrique Otero CARVAJAL y Rubén PALlOL TRIGUEROS, La sociedad urbana en España, 1900-1936, Madrid, Catarata, 2017, pp. 132-163.

11. Jorge URía GonZÁlEZ, "Sociabilidad informal y semiótica de los espacios. Algunas reflexiones de método”, Studia Histórica. Historia Contemporánea, 26 (2011), pp. 177-212; Joan MuÑoz GONZÁLEZ, "En el espacio leemos el tiempo. Reflexión historiográfica para una historia del presente", Historia Actual Online, 48 (2019), pp. 145-157.

12. La visión del espacio sociogeográfico y la interpretación desde lo objetual y cosmológico es una propuesta de Flora LOSADA en "El espacio vivido. Una aproximación semiótica”, Cuadernos de la Facultad de Humanidades y Ciencias Sociales, 17 (2020), pp. 1-25.

13. Joan Manuel NARANJO, "Espacios de uso público: una nueva realidad sociogeográfica de marginalidad territorial en la periferia barrial”, Contextos: estudios de Humanidades y Ciencias Sociales, 40 (2018). 
segundo epígrafe, dominado por la comparación y la interpretación, se contextualiza desde la microhistoria la realidad municipal en la semiótica y representación de la agrociudad por parte de distintos grupos sociales. Aquella es, como veremos, conflictiva, al constituir un espacio de encuentro y de desencuentro entre dos o más cosmovisiones diferentes.

Para la interpretación histórica de Arcos como agrociudad, además de las fuentes tradicionales de archivo, hemeroteca y entrevistas orales, se utiliza cartografía como parte integral del método científico. Aprovechamos las herramientas digitales disponibles, que han permitido la digitalización y la georreferenciación de mapas históricos y su construcción personalizada. Al hilo de lo destacado en revistas científicas como Urban History, tratamos de sumar otros puntos de vista con la extrapolación de datos a la representación cartográfica. Además de pensar la Historia espacialmente, se trata, una vez más, de aprovechar la interdisciplinariedad y utilizar instrumentos beneficiosos para avanzar en la comprensión histórica ${ }^{14}$.

Finalmente, y recogiendo las propuestas de Alberto Matarán, Dorothee Brantz y Lois McNay hemos creído conveniente incluir descripciones del paisaje de la agrociudad desde la representación de quien la pisaba en el primer tercio del siglo XX, señalando su significado y prestando atención a su identidad y a los elementos que participan en su actividad ${ }^{15}$.

\section{Contextualización histórica y espacial. Arcos de la Frontera en el primer tercio del siglo xx: su identificación morfológica y productiva como agrociudad}

Arcos de la Frontera es una localidad situada en la Baja Andalucía, entre la campiña y la sierra de Cádiz. Constituye el segundo término municipal más amplio de la provincia y a comienzos del siglo XX daba nombre al partido judicial en el que se aglutinaban poblaciones como la propia Arcos, Espera, Bornos, Villamartín, Algar y Prado del Rey. De fértiles campos, la ciudad está encaramada en una montaña erosionada en sus caras norte y sur y rodeada por el río Guadalete. Por su término municipal han transitado diferentes culturas desde la Prehistoria. El origen de la trama urbana que ocupa Arcos en la primera mitad del siglo XX hay que buscarlo en la irrupción musulmana en la Península Ibérica. Es ésta la que motiva el aprovechamiento de una fortaleza natural (arx-arcis) como espacio de poblamiento, con la realidad de frontera y las experiencias bélicas medievales, que la consolidaron como un área de

14. Leif JERRAM, “Space: a useless category for historical analysis?”, History and Theory, 52 (2013), pp. 400-419 (https://doi.org/10.1111/hith.10676); Richard RODGER y Susanne RAU, "Thinking spatially: new horizons for urban history”, Urban History, 47 (2020), pp. 372-383 (https://doi.org/10.1017/S0963926820000218); Olaf MARZ, "An urban-rural continuum? A spatial comparison in mid-eighteenth-century northern Germany”, Urban History, 47 (2020), pp. 421-447 (https://doi.org/10.1017/S096392682000022X). El beneficio de usar cartografía histórica en José Luis ANTA FÉLEZ, "La cartografía histórica como instrumento de análisis territorial el caso de las nuevas poblaciones de Sierra Morena”, en Juan Antonio MÁRQUEz DomínguEz y Jorge Llamas ChÁvEZ, Hélices y anclas para el desarrollo local, Huelva, Diputación de Huelva, 2019, pp. 1.187-1.201.

15. Alberto MAtarán RuIZ, "Propuesta metodológica para el análisis identitario del paisaje”, Urban NS05, (2013), pp. 19-62; Dorothee BRANTZ, "Assembling the multitude: questions about agency in the urban enviroment”, Urban History, 44, 1 (2017), pp. 130-136 (https://doi.org/10.1017/S0963926816000304); Lois MCNAY, “Agency and experience: gender as a lived relation”, The Sociological Review, 52 (2004), pp. 173-190 (https://doi.org/10.1111/j.1467954X.2005.00530.x). 
referencia por su posición privilegiada en el control de territorio ${ }^{16}$. Desaparecida la motivación guerrera y el contexto de frontera entre las culturas musulmana y cristiana, lo sorprendente es que durante todo el siglo XX, y a pesar de su difícil orografía, los arcenses siguieran habitando estructuras urbanas del pasado medieval, $\mathrm{y}$ en un apego memorial, desarrollaran su vida cotidiana elevados sobre dos peñas, con el río Guadalete abajo, en vez de junto a la cómoda y fértil llanura.

Mapa 1: Término municipal de Arcos

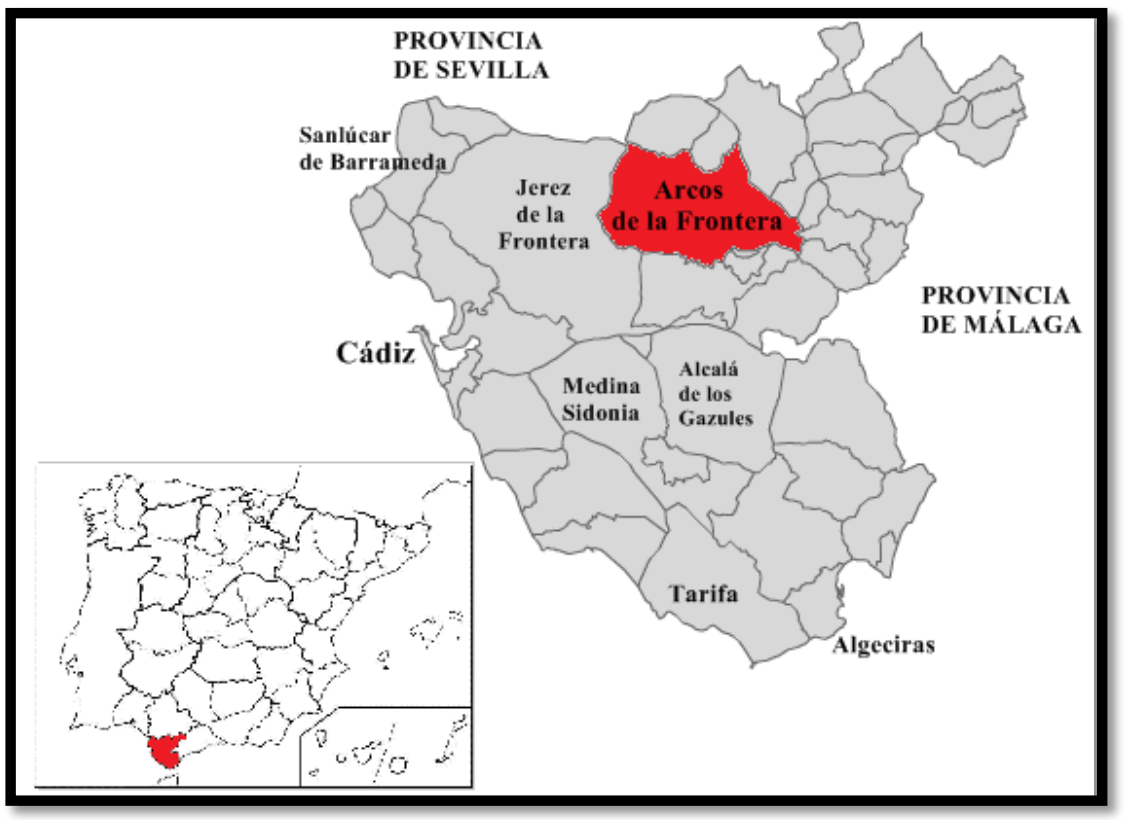

F.: elaboración propia.

El término municipal de Arcos en las tres primeras décadas del siglo XX ya era uno de los mayores de la provincia, lo que hacía que existiese una considerable variedad en cuanto al poblamiento del hábitat rural: aldeas, pedanías o cortijos. En 1930 destacaban como entidades poblacionales rurales: Jédula, que distaba unos once kilómetros del casco urbano y donde habitaban en chozas diseminadas unas 380 personas censadas; Parrilla Alta y Parrilla Baja, a unos cinco kilómetros, con una población de 143 y 170 personas respectivamente; El Roncero, a unos cinco kilómetros y medio, donde habitaban 149 personas; El Romeral, a poco menos de dos kilómetros, habitado por 105 arcenses, y El Guijo, que se encontraba a 500 metros y donde habitaban 119 personas ${ }^{17}$. Por lo general, se trataba de asentamientos rurales situados en la campiña, al suroeste de su término, cercano a las fértiles tierras de grandes cortijos, como Casablanca, Jedulilla, Los Majadales o El Lotabón.

16. Su topónimo en sí mismo ya es un compendio del territorio ocupado y de la identidad de sus moradores. María Jesús ViguerA Molins, “Arcos en al-Andalus: notas sobre su historia islámica” en Actas I Congreso de Historia de Arcos de la Frontera", Arcos de la Frontera, Excmo. Ayuntamiento de Arcos, 2003, pp. 31-55; Manuel GonzÁLEz y Rafael SÁNCHEZ (coords.), Arcos y el nacimiento de la frontera andaluza (1264-1330), Sevilla, Universidad de Sevilla-Universidad de Cádiz, 2016.

17. Entre aldeas, cortijos y pedanías sumaban 212 (ARCHIVO HISTÓRICO MUNICIPAL DE ARCOS DE LA FRONTERA -en adelante, AHMAF-, Sig. 1.652, Exp. Censo de población 1930-1931). 


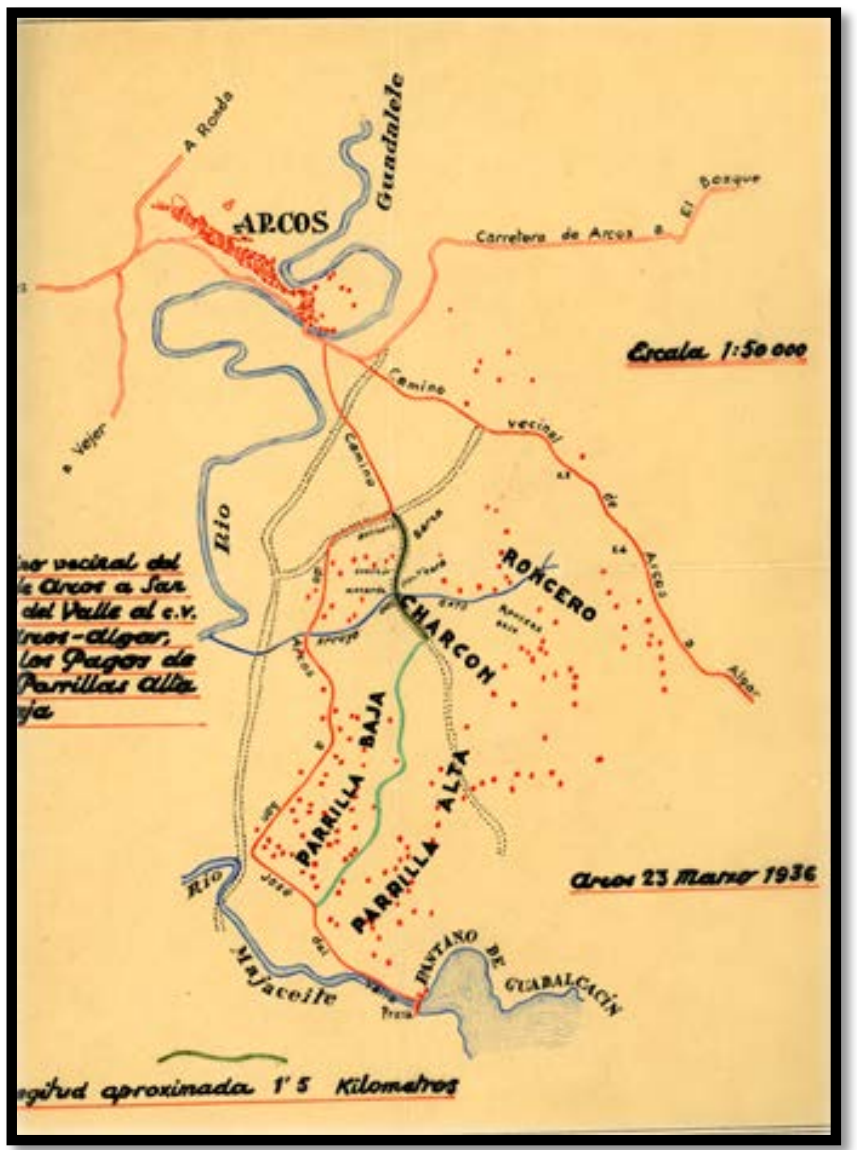

F.: AHMAF. Sig. 588.

Mapa 3: Entidades poblacionales del Arcos urbano y rural

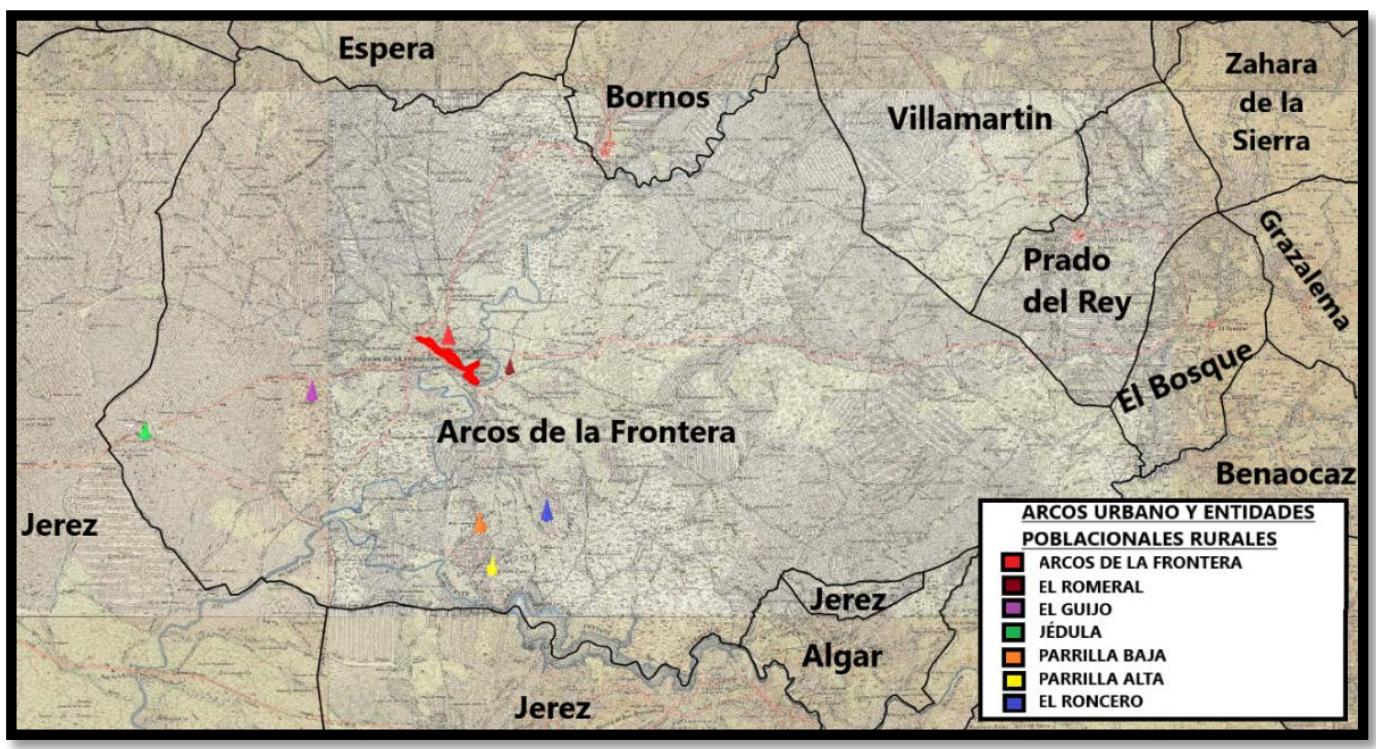

F: elaboración propia con los datos de este estudio y la representación cartográfica histórica del Instituto Nacional de Geografía.

En cuanto a la población y su densidad, a inicios del siglo XX, después de perder más de dos mil habitantes, la ciudad volvió a superar los 14.000 vecinos y llegó hasta los 19.563 habitantes en 1936. En este período de tiempo, un gran porcentaje se sigue concentrando alrededor del casco histórico, que se divide en siete secciones, sin otra estructura urbana en su extenso y amplio término municipal, a excepción de los 
pequeños poblados rurales sin rasgos de urbanidad que se pueden observar en el mapa anterior. En el mismo se ilustra cómo en el primer tercio del siglo XX, en apenas un 0,17\% del término municipal, esto es, en el Arcos urbano, se concentra el $64 \%$ de sus habitantes ${ }^{18}$. En este sentido, lo que prima en este momento en la ciudad es la idea que se ha destacado desde la Antropología y la Sociología para el caso de las agrociudades: el deseo de sus habitantes por la concentración, la densidad y la "pasión por el bullicio" frente a la soledad del campo ${ }^{19}$.

Gráfico 1: Evolución de la población en Arcos desde 1877 a 1936

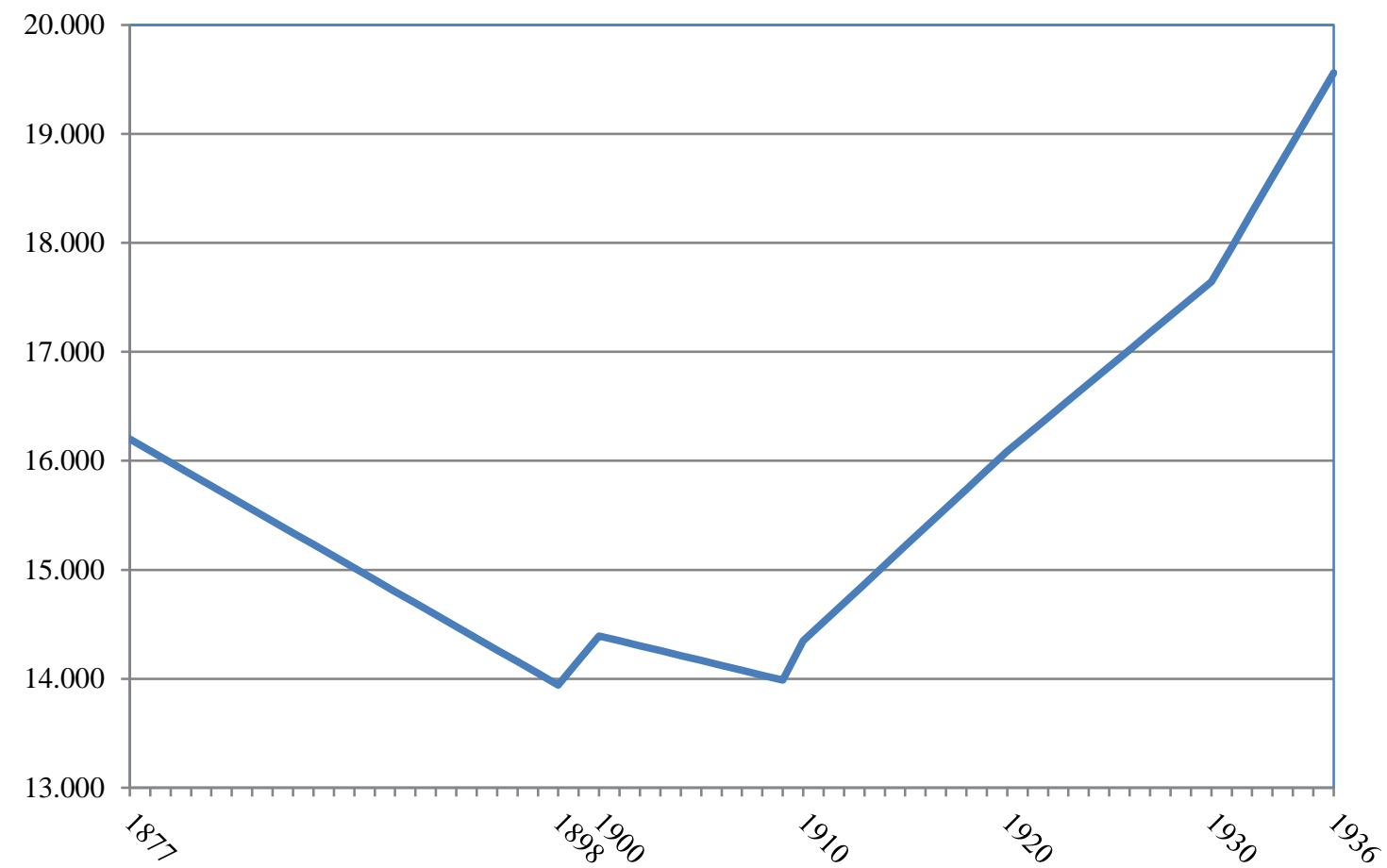

F.: Elaboración propia datos del INE (Censos de población 1887, 1900, 1910, 1920 y 1930) y AHMAF, Sig. 564, Padrón vecinal 1898; Sig.568, Padrón municipal de diciembre de 1935.

Las actividades económicas en la agrociudad y, por extensión en Arcos, giraban en torno al sector primario, fundamentalmente agricultura y ganadería. En relación a otros sectores, si en la industria local existían fábricas de jabón, cera, gaseosa, hielo o harinas, muchas de las cuales empleaban electricidad, lo que primará será un tipo de explotación tradicional y más rudimentaria en torno a la transformación de materias primas, como la cal, la aceituna y el trigo, así como talleres para trabajar el barro, el cuero, la palma y otros tejidos. El comercio, sin ser deficiente, era pequeño, y en contadas ocasiones, mediano. Aun así, cubrían las necesidades de abastecimiento de la población. Desde el punto de vista de la distribución y localización, como podemos ver en los siguientes mapas, las fábricas se situaban principalmente a las afueras de la

18. En metros cuadrados, el término comprendía un total de 503.128.775, de los cuales 900.000 correspondían a zona urbana, 30.000 .000 a forestal, 472.938 .775 a agrícola y 60.000 a minera (AHMAF, Sig. 510, Expediente de datos estadísticos, 1932). Los datos de la población urbana y rural, que apenas variaron en las tres primeras décadas de la centuria, en Ibídem, Sig.564, padrón vecinal 1898; Sig.568, Cuaderno auxiliar de empadronamiento municipal 1930.

19. Se trata de una idea de BLOK y DRIESSEN citada por LóPEZ-CASERO, “Identidad...”, p. 80. 
población (secciones $3^{\mathrm{a}}$ y $7^{\mathrm{a}}$ ), cercanas al río, mientras que dentro del casco histórico primaban los talleres de zapatería, carpintería o sastrería ${ }^{20}$.

Mapas 4, 5, 6 y 7: Ubicación del comercio, la restauración, las industrias y otros servicios en Arcos entre 1924 y 1926.

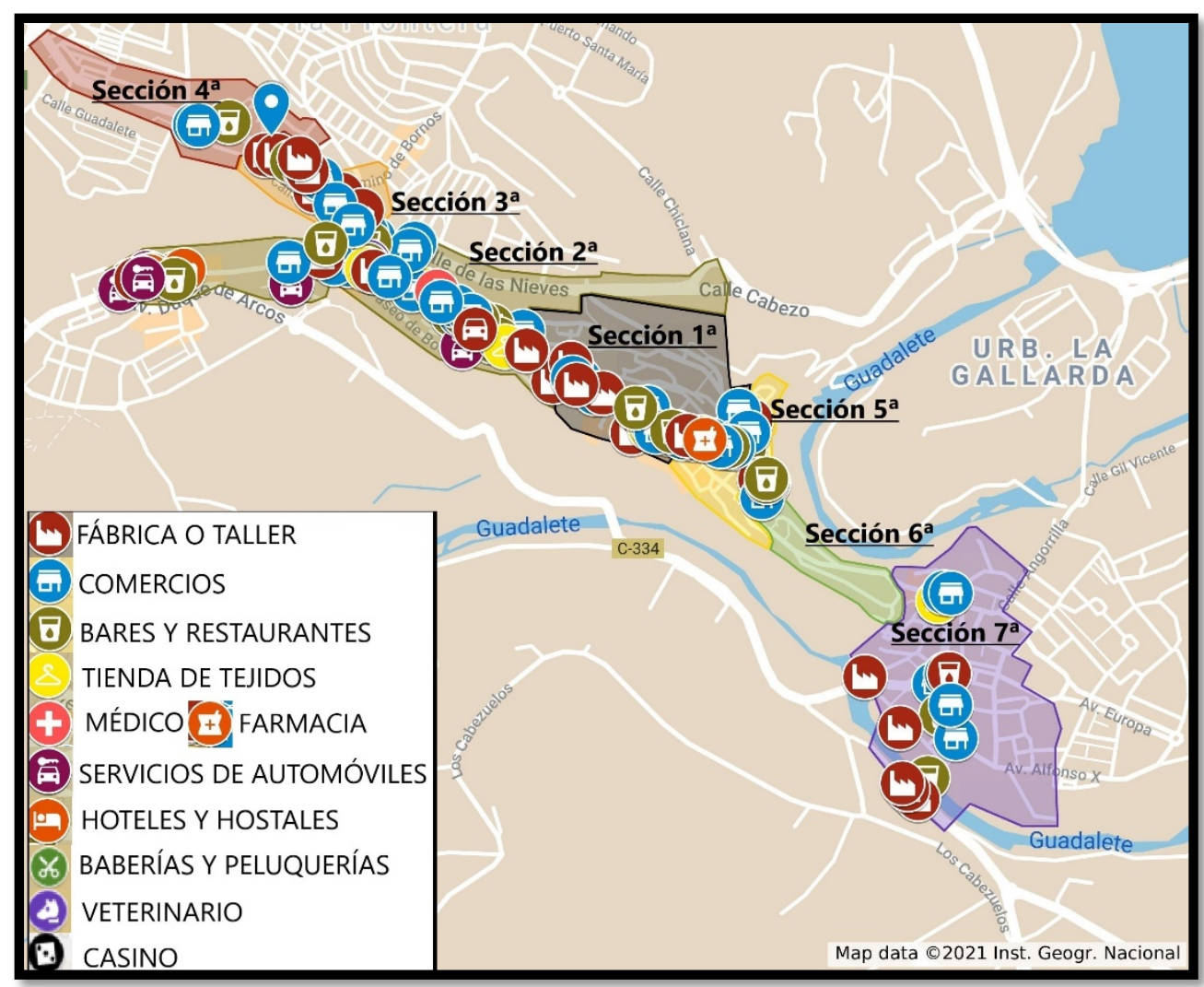

20. Hemos realizado un acercamiento al comercio y a la industria local, y a su localización espacial proyectando los datos que aparecen en las revistas de feria de 1924 y 1926 que hemos consultado en el ARCHIVO FAMILIAR DE MANUEL PÉREZ REGORDÁN [en adelante AFMPR]. Tomando como referencia los anuncios de los comercios y las fábricas insertados en la publicidad -sin ser todos, sino aquellos de más pedigrí-, hemos realizado una representación cartográfica que creemos que puede ser bastante cercana a la realidad del primer tercio del siglo XX. Con el icono de tienda figuran los siguientes comercios: almacenes de comestibles, fondas de comercio, abacerías, hojalaterías, perfumería, quincalla, paquetería, droguerías, estancos, coloniales, carnicerías, relojería, ferreterías, sombrererías, tienda de abonos, oficinas de seguro, representantes de bebidas y productos químicos para la agricultura. Con el icono de fábrica, zapaterías, carpintería y ebanistería, talleres de carros, herrerías, sastrería, cerrajería y fábricas de harina, de jabón, gaseosa y agua de seltz; con el de bar, cervecerías, bares, cafeterías y restaurantes. 

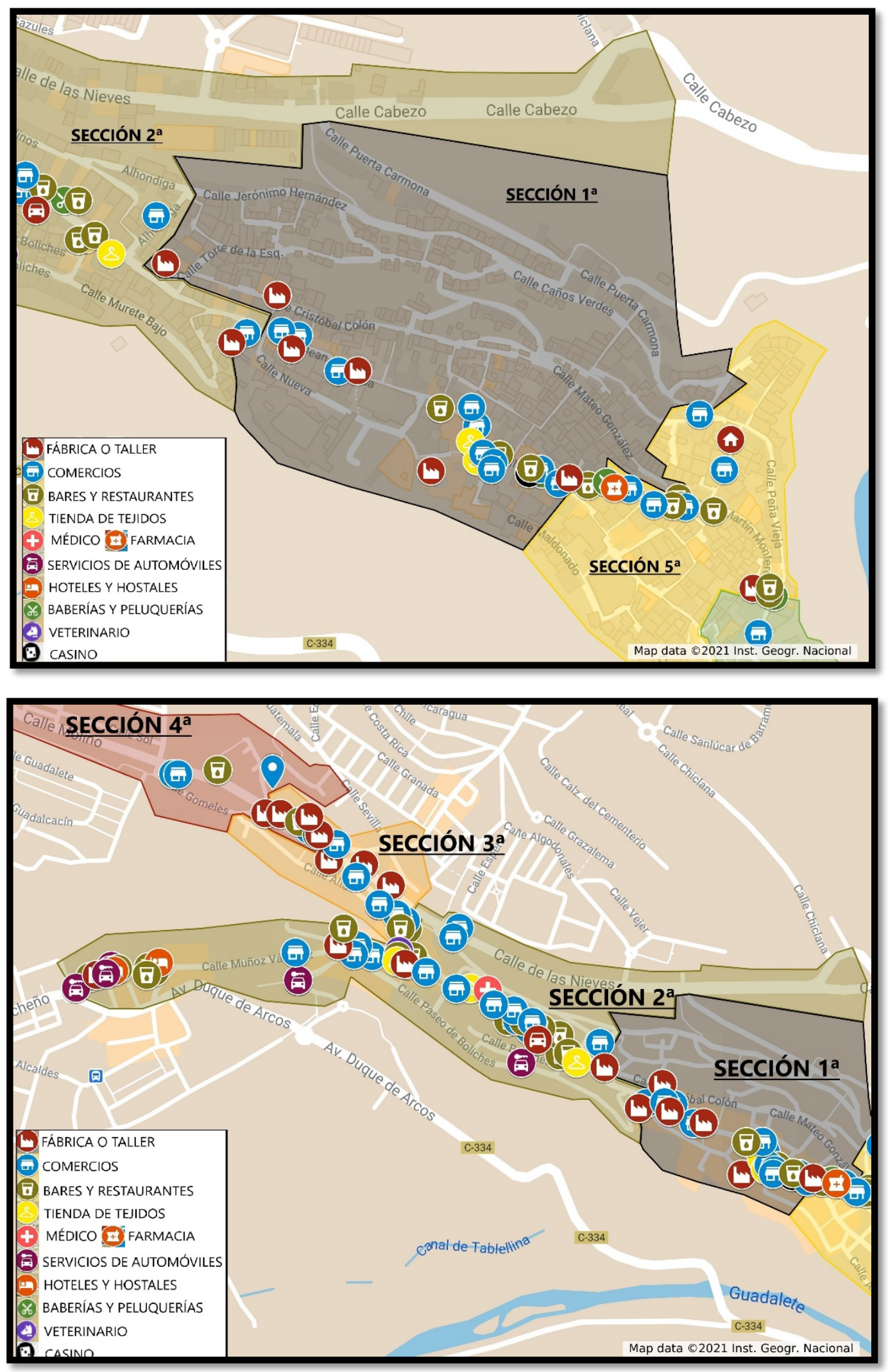


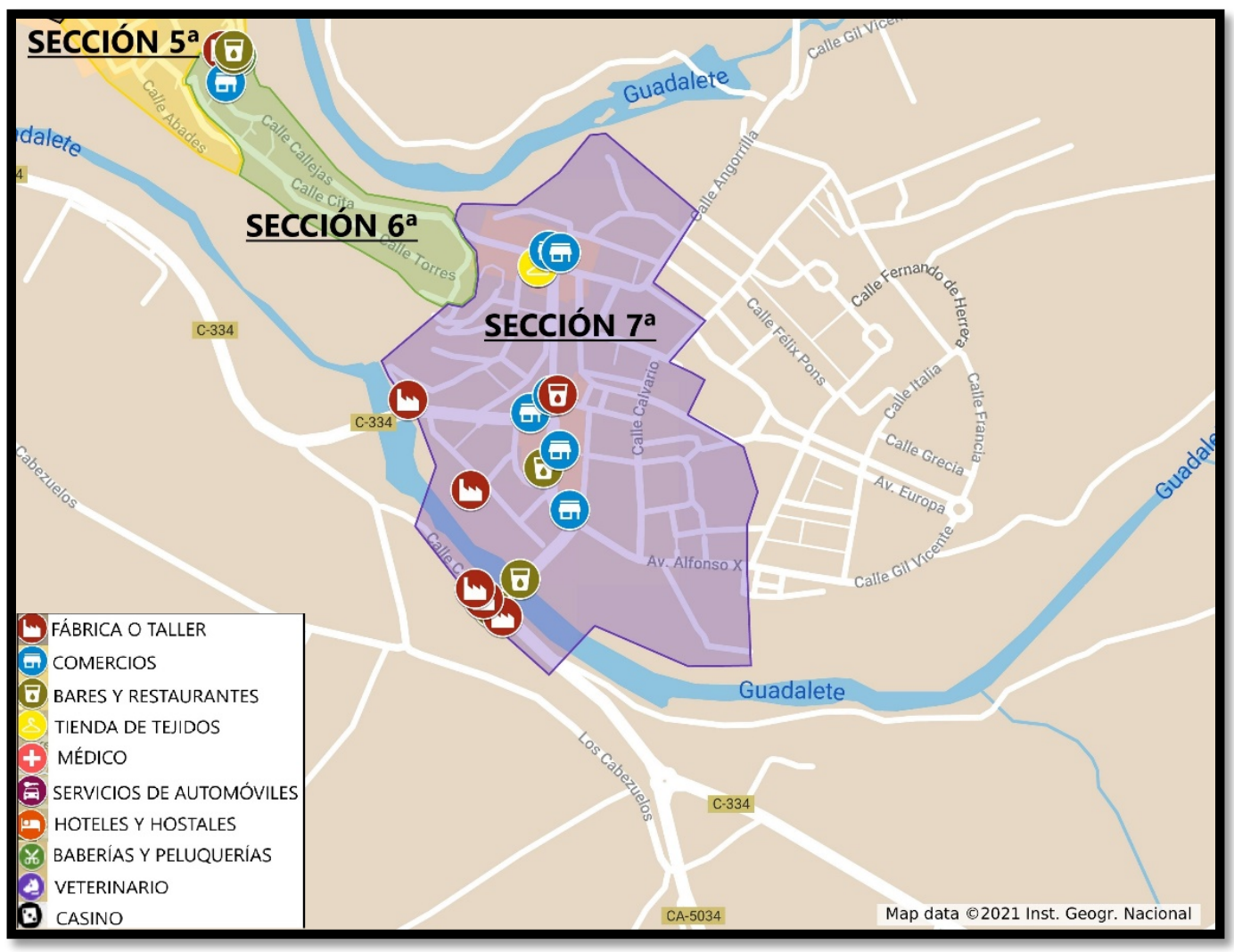

F.: Elaboración propia y personalizada en la plataforma de Google My Maps con los datos obtenidos de Revista de Feria 1924 y 1926 procedentes del AFMPR.

A pesar de las revoluciones liberales y de los no pocos y conflictivos repartos de tierras y desamortizaciones, la estructura de la tierra local sigue los cánones tradicionales, con el cultivo de la triada mediterránea y la concentración de la propiedad en pocas manos ${ }^{21}$. La ganadería en el primer tercio del siglo XX, aun siendo importante, no era más que un espejismo de lo que fue para el engrandecimiento del nombre de la ciudad $^{22}$.

En cuanto a la estructura de la tierra y a la propiedad del espacio, a la altura de la tercera década del siglo XX Cádiz es "la provincia en que más importancia relativa tienen los latifundios”, porque "de las 687.153 hectáreas útiles catastradas, el 58 por 100, 398.342 hectáreas, se encuentran en fincas mayores de 250”. Para el caso concreto de Arcos, “entre 87 propietarios reúnen el 79 por 100 de la riqueza total” y un 56,87 por ciento del término municipal era latifundio ${ }^{23}$. En este sentido, como señala López-

21. En 1930, 54.217,25 fanegas se dedicaban a la siembra de cereales y legumbres, 9.374 a olivar, 14.216 a monte bajo y alto, ríos y caminos y 5.567 a otros cultivos. Resultando un predominio de los cultivos de cereales y legumbres, correspondiendo el 64 por ciento del total de las fanegas a estos productos de secano. Otra de las grandes actividades era el trabajo del corcho de alcornoque (AHMAF, Sig. 573, exp. 6).

22. Las causas del declive del sector eran "la falta de capitales, la de medios de comunicación y la competencia que ventajosamente hacen los productos extranjeros” (Miguel MANCHEÑO OLIVARES, Apuntes para una historia de Arcos, Arcos, Ayuntamiento de Arcos, 2002, p. 195). En los años 1930 constituía vagamente un complemento económico, mediante la cría de ovejas, cabras, cerdos, gallinas, pollos y vacas (AHMAF, Sig. 434, exp. 9).

23. Pascual CARrión, Los latifundios en España, Madrid, Ariel, 1975, pp. 234 y 236. 
Casero, en la estructura socioeconómica básica de las agrociudades podemos diferenciar dos grupos: uno agrario y otro no agrario ${ }^{24}$. También una sociedad con marcadas desigualdades provenientes de la tenencia de la propiedad de la tierra, que era controlada por una minoría social endogámica, en un gran porcentaje forastera, como demuestra el estudio que hemos realizado del padrón de contribuyentes del año $1929^{25}$.

Cuadro 1: Mayores contribuyentes de Arcos en 1929

\begin{tabular}{|c|c|c|c|c|}
\hline \multirow{2}{*}{ NOMBRE } & \multicolumn{3}{|c|}{ LÍQUIDO IMPONIBLE (PTS.) } & \multirow[b]{2}{*}{ RESIDENCIA } \\
\hline & RÚSTICA & URBANA & INDUSTRIA & \\
\hline $\begin{array}{l}\text { ARMERO MANJÓN, PEDRO, C. DE } \\
\text { BUSTILLOS } \\
\text { BOHÓROUEZ OLIVA. ÁNGEL }\end{array}$ & $35.032,72$ & 1.226 & - & $\begin{array}{l}\text { Forastero } \\
\text { Forastero }\end{array}$ \\
\hline $\begin{array}{l}\text { BOHÓRQUEZ OLIVA, ÁNGEL Y } \\
\text { MIGUEL } \\
\text { BOHÓRQUEZ OLIVA, MIGUEL }\end{array}$ & $\begin{array}{l}27.807,37 \\
31.511,29\end{array}$ & 150 & - & $\begin{array}{l}\text { Forasteros } \\
\text { Forastero }\end{array}$ \\
\hline CUEVAS OLIVARES, FRANCISCO & $27.260,73$ & 838 & - & Vecino \\
\hline GONZÁLEZ RUIZ, DIEGO & $44.139,48$ & 2.846 & 708 & Vecino \\
\hline GUARDIOLA YZUIYER, SALVADOR & $47.854,75$ & - & - & Forastero \\
\hline MARTEL VIDAL, FRANCISCO & $85.324,43$ & 6.480 & - & Forastero \\
\hline MARTEL VIDAL, ENCARNACIÓN & $40.516,79$ & 1.128 & - & Forastera \\
\hline $\begin{array}{l}\text { MONTERO GARCÍA DE VEAS, } \\
\text { CONCEPCIÓN }\end{array}$ & $24.816,48$ & 2.187 & - & Vecina \\
\hline $\begin{array}{l}\text { MORENO LLAMAS, MANUEL Y } \\
\text { HNO. }\end{array}$ & $60.896,71$ & 480 & - & Vecinos \\
\hline $\begin{array}{lrrr}\text { DE } & \text { LOS } & \text { RÍOS } & \text { MONTERO, } \\
\text { FERNANDO } & & \end{array}$ & $38.204,00$ & 176 & - & Vecino \\
\hline $\begin{array}{ll}\text { RODRÍGUEZ } & \text { VIDAL, } \\
\text { ENCARNACIÓN Y NIEVES } & \end{array}$ & $28.206,56$ & 568 & - & Vecinas \\
\hline RODRÍGUEZ GONZÁLEZ, JUSTO & $33.049,73$ & - & - & Forastero \\
\hline $\begin{array}{l}\text { RUIZ ORTIZ, FRANCISCO DE } \\
\text { PAULA } \\
\text { RUIZ ORTIZ, MANUEL Y MARÍA }\end{array}$ & $66.072,00$ & 1.644 & - & $\begin{array}{l}\text { Forastero } \\
\text { Forasteros }\end{array}$ \\
\hline SALAS MARTEL, MANUELA & $61.591,26$ & 2.208 & - & Vecina \\
\hline SALAS VÁZQUEZ, FELIPE & $78.926,24$ & - & - & Forastero \\
\hline $\begin{array}{l}\text { VELÁZQUEZ-GAZTELU, JOSÉ } \mathbf{M}^{\mathrm{a}} \text {, } \\
\text { M JOSEFA Y FCO. JAVIER }^{\mathrm{a}} \text { VELÁZQUEZ-GAZTELU, JUAN JOSÉ } \\
\text { YE FCO. J. }\end{array}$ & $30.310,40$ & - & - & Vecinos \\
\hline
\end{tabular}

F.: Elaboración propia con datos de AHMAF, Sig.144, Libro contribuciones de 1929.

Si analizamos los datos extraídos, de los veinte primeros contribuyentes, once tenían residencia en otro lugar que no era Arcos. Si estiramos la lista hasta los veintiocho primeros contribuyentes, se acentúa la situación, pues son dieciocho los mayores contribuyentes que no residen en la agrociudad. Todavía más significativo es

24. LÓPEZ-CASERO, “Identidad...”, p. 79.

25. AHMAF, Sig. 144, Libro contribuciones de 1929. 
que de los noventa y seis primeros contribuyentes, tan solo treinta y siete sean vecinos $^{26}$.

Se trataba de una burguesía provincial agraria y absentista que controlaba la tierra y los sistemas de producción. Por poner algunos casos como ejemplos, con respecto a los datos del cuadro, en primer lugar tenemos a la familia de los Bohórquez Oliva, formada por los hermanos Miguel y Ángel, a los que podríamos atribuir más riqueza imponible de la que aparece en el cuadro, ya que por otra parte Ángel tenía junto con su esposa un líquido en pesetas de 7.067,84. El patrimonio familiar no se limitaba a Arcos, ya que Ángel Bohórquez también era, en 1930, el sexto mayor contribuyente de Jerez, pues poseía en este último término 15.740,02 de riqueza rústica ${ }^{27}$. Asimismo, era cuñado de los hermanos Ruiz Ortiz, de Bornos ${ }^{28}$.

Los Ruiz Ortiz formaban otra de las familias que se encontraban entre las que mayor riqueza imponible se les atribuía, y Francisco de Paula, de su familia, era quien tenía más tierras en el término de Arcos. Otra familia que tampoco residía en el pueblo, pero poseía la tierra, era la de los Martel Vidal, Encarnación y Francisco. Este último era el primer contribuyente por rústica con un líquido en pesetas de 85.324,43 y 6.479,75 por urbano, a los que se le puede sumar la cifra de 7.591,82 de líquido imponible que poseían juntos, por otra parte, Francisco y Encarnación Martel Vidal y Manuela Salas Martel. Esta última, con residencia en Arcos, también acaparaba un líquido imponible de 61.591,26 pesetas por rústica y 2.208 por urbana. En el segundo puesto de mayor contribuyente encontramos a otro forastero, Felipe Salas Vázquez, con un total de 78.926,24 y entroncado familiarmente con la familia Velázquez-Gaztelu. Entre otros, formaban parte de los mayores contribuyentes del término los forasteros: Salvador Guardiola Iyázquez, Justo Rodríguez González o el alcalde de Sevilla y más tarde líder de la CEDA, Pedro Armero Manjón, conde de Bustillos.

Asimilando este retrato socioeconómico determinado por la propiedad del espacio en 1930, poco había cambiado la situación desde que en 1900 José Olivares Veas escribiera:

Los hacendados forasteros representan próximamente el 50\% de la total riqueza [...] hay aún más, figuran como vecinos, contribuyentes de verdadera importancia, entre ellos el primero D. Francisco de Asís Martel, y uno de los primeros el Excmo. Sr. D. Pedro J. Moreno Rodríguez residiendo constantemente con sus respectivas familias, el Sr. Martel en la vecina ciudad de Jerez de la Frontera y el dicho Sr. Moreno Rodríguez en Madrid $^{29}$.

Que la propiedad de gran parte del espacio y la fuente de riqueza en Arcos estuviese en manos de una minoría y que ésta, además, en un gran número fuese forastera, acrecentaba los problemas de los vecinos de la localidad y creaba tensiones con otras localidades, como Jerez y Bornos. José Olivares Veas aclaraba en 1900:

No solo faltan los propietarios, sino los colonos que labran la mayor parte de las fincas del término que son vecinos de otros pueblos. Los Cortijos de Jédula, Jedulilla, La Torre, El Palomar, San Rafael, El Toril, Las Posadas, Albrajanejo, Alperchite y otros, es decir la casi totalidad de los predios laborables están como se ha dicho colonizados por

26. Ibídem.

27. Para Jerez, CARO, Violencia política y luchas sociales, p. 29.

28. Fernando Romero Romero, "Labradores y caciques: los Ruiz Ortiz, una familia conservadora de Bornos (1897-1938)”, Almajar, 5 (2015), pp. 1-19.

29. AHMAF, Sig. 573, exp. 28.

Rubrica Contemporanea, vol. X, n. 19, 2021. 
forasteros, estos como es natural tienen sus aperadores y temporiles de sus mismos pueblos y prefieren a los braceros de sus respectivas localidades por estar unidos con lazos de amistad o parentesco, trayendo por consiguiente una disminución de trabajo a la localidad que se traduce todos los años en falta de medios de subsistencia ${ }^{30}$.

Si a esta problemática añadimos que la mayor parte de la población era jornalera y las condiciones de vida que devienen de ello, en la agrociudad gaditana existía una situación proclive al enfrentamiento político-social por el espacio, nacida siglos atrás y que aflorará en contextos propicios, como la Regencia de Espartero, el Bienio Progresista, la Revolución de 1868, la crisis de la Restauración o la Segunda República ${ }^{31}$. Si la revisión de los datos de dispersión demográfica nos puede dar una idea aproximada de la importancia del espacio agrícola en el Arcos de 1930, el análisis socioprofesional del padrón vecinal de 1917 nos aporta una visión más completa. De un total de 4.191 de población activa masculina, considerando en ésta a los hombres a los que se les adjunta una profesión en el padrón, 3.168 tienen la denominación de "campo" o “jornalero”. En relación a la ocupación espacial, en el Arcos urbano el 67,3\% de la población activa se dedicaba al campo y en el ámbito rural el 91,3\%. Frente a esto, una minúscula parte de los vecinos tenía como definición "propietario" o "profesional liberal" en el Arcos urbano, tan sólo 175 personas de 2.784, lo que viene a representar el $6,2 \%$ de la población. Del resto de oficios, el padrón aporta un proletariado urbano débil si lo comparamos con el campesinado y una minúscula clase media dedicada al comercio y a la actividad industrial, además de los propietarios y labradores ${ }^{32}$.

En este sentido, una marcada disociación y enfrentamiento entre distintos grupos sociales es lo que va a primar a lo largo del primer tercio de siglo XX. Se trata de un conflicto por el espacio, que es sin duda el gran eje vertebrador de la agrociudad gaditana. De la tenencia o no de la tierra devienen no solo el bienestar económico, las condiciones de vida y el capital social, sino también diferentes formas de habitar y representar la realidad y el territorio, como veremos a continuación.

\section{Ethos urbano y semiótica de la agrociudad. Arcos como espacio de encuentro y desencuentro}

Eran las once de la mañana del domingo 18 de noviembre de 1917 y todos los amigos políticos del Partido Conservador llegaban a la casa del rico e influyente Juan José Velázquez-Gaztelu y Caballero-Infante. El sistema oligárquico se degradaba a nivel municipal. La candidatura conservadora-liberal había perdido las elecciones frente a romanonistas, datistas y republicanos. Al acto asistían caciques provinciales, como el

30. Ibídem. Estas tensiones se avivaron durante la Segunda República con la Ley de Términos Municipales (AHMAF, Sig. 118, Actas Capitulares [en adelante AC] 16-12-1932, pp. 124-125; 23-121932, p .131; Sig.119, AC, 26-5-1933, p. 277; 23-6-1933, pp. 296-298; 19-5-1933, p. 275).

31. Uno de los conflictos de más relevancia se dio en 1841, cuando los jornaleros tomaron la ciudad, y se enfrentaron violentamente a las autoridades para que se efectuaran repartos de lotes de tierras. Durante todo el siglo XIX, en contextos propicios se repiten estos enfrentamientos por el espacio. En 1868 los vecinos de Arcos, Bornos y Paterna se lanzan a ocupar las tierras de las clases acomodadas y/o a hacerse con sus frutos (Antonio OrTEga CAStillo, "La Revolución de 1868 en la Sierra de Cádiz: Arcos de la Frontera”, en Diego CARo CANCELA (coord.), La revolución de 1868 en Andalucía, Madrid, Peripecias Libros, Madrid, 2018, pp. 141-165). Sobre las diferencias sociales en la agrociudad, Francisco LÓPEZCASERO, "Sobre la desigualdad social en las agrociudades mediterráneas: una aproximación metodológica”, Revista Internacional de Sociología, 25 (2000), pp. 179-206.

32. AHMAF, Sig. 567, Padrón vecinal de 1917.

Rubrica Contemporanea, vol. X, n. 19, 2021. 
conde de los Andes o Joaquín Pérez Lila. Otros, como Juan José Rivero, enviaban un telegrama. Se trataba de arropar con un banquete la flagrante derrota de la joven promesa del conservadurismo local, José Olivares Piña. Su impecable trayectoria había sufrido un revés. Era hijo del antiguo jefe conservador, José Olivares Veas, ingeniero electricista, y regentaba la fábrica de harinas más moderna de la comarca. Dos años antes había sido nombrado regidor por el artículo 29 y constituía una desdicha que no ocupase un lugar en el Consistorio municipal. Se había presentado por el tercer distrito electoral, que comprendían las secciones $6^{\mathrm{a}}$ y $7^{\mathrm{a}}$, el barrio de San Agustín y el Barrio Bajo. Si los líderes tradicionales buscaban en supuestas coacciones y presiones las causas de la derrota, lo cierto es que el hecho de presentarse como candidato en un distrito poblado por vecinos de escasos recursos fue con toda seguridad la razón de su descalabro en los comicios ${ }^{33}$.

A comienzos de siglo, el obrero Andrés Escot Garrucho había liderado la creación de sociedades de resistencia de carácter republicano. Residente en la sección $3^{\text {a }}$, se hizo eco de las predicaciones de Manuel Moreno Mendoza, que hizo extensible al mundo rural de la campiña y la sierra de Cádiz el republicanismo reformista de Lerroux que hasta entonces era predominante en las grandes urbes. Escot había fundado en 1899 la Sección Varia y en 1911 la reconvertiría en Sociedad Fraternidad Obrera. Junto con la labor de Moreno Mendoza, Escot y otros, la residencia en la ciudad de Rafael Pérez del Álamo durante sus últimos años influyó en la popularización de los ideales democráticos y antidinásticos entre los trabajadores. Así, cuando amanece la nueva centuria, el republicanismo desplaza al anarquismo como ideología dominante en la zona y las urnas comienzan a llenarse de papeletas que apoyan a los antidinásticos en la crisis de la Restauración, al tiempo que arraigan en la práctica social exposiciones públicas de este ideal con tradicionales celebraciones como las del primero de mayo, giras o mítines ${ }^{34}$.

En ese año de 1917, en las secciones que correspondían al segundo y tercer distrito electoral era donde había mayor porcentaje de vecinos dedicados al agro y se correspondían con las áreas en las que solían recibir más apoyos los candidatos republicanos ${ }^{35}$. Para entonces, y en relación a lo que se ha denominado como mapa

33. Sobre el banquete y José Olivares, El Guadalete, 21-11-1917, p. 1; 19-2-1915, p. 1; 23-1-1920, p. 3; 11-4-1922, p.1; El Eco de Arcos, 16-3-1916, p. 2.

34. Hace unos años se destacó la necesidad de ofrecer una nueva concepción de la historia política de Andalucía que dejara a un lado la visión de fracaso para destacar sobre ella el papel desarrollado en la modernización política y la democratización. Defendemos que, en este fenómeno, las ciudades medias de Andalucía, es decir, las agrociudades, fueron un espacio esencial. Vid. Manuel GonzÁLEZ DE MoLINA (coord.), Historia, identidad y construcción de la ciudadanía. Por una relectura de la historia contemporánea de Andalucía, Fundación Centro de Estudios Andaluces, 2007, https://www.centrodeestudiosandaluces.es/publicaciones/historia-identidad-y-construccion-de-la-

ciudadania-por-una-relectura-de-la-historia-contemporanea-de-andalucia (consultado en 15-4-2021). Sobre Moreno MendozA, Manuel Morales Benítez, Prensa, masonería y republicanismo. Manuel Moreno Mendoza, (1862-1936) y la masonería jerezana, Jerez, Ayuntamiento de Jerez, 2008. El republicanismo y el papel de Escot en Antonio ORTEGA CASTILLO, "Protestas obreras y actitudes sociales en el Arcos de 1918-1920”, Almajar, 5 (2015), pp. 1-25; ídem, “Conflictividad en la campiña: las huelgas de los obreros arcenses en el primer bienio republicano”, en Diego CARO CANCELA (coord.), El movimiento obrero en Jerez y su entorno (siglo XIX y XX), Cádiz, Editorial UCA, 2015, pp. 221-234. Sobre el republicanismo y sus expresiones en el espacio público, El Arcense, 15-4-1909, p. 2; 1-5-1909, p. 3; El Pueblo, 21-1-1912, p. 3; El Guadalete, 18-2-1902, p. 3; 5-5-1918, p. 1. La Vanguardia, 15-111909, p. 5.

35. AHMAF, Sig. 567, Padrón vecinal de 1917; Sig. 1.478, Elecciones locales. 
socioecológico, podemos decir que Arcos tenía una población concentrada en el casco histórico, y aunque dentro del mismo no existía una separación categórica en cuanto a residencia en función de estatus socioeconómico, sí era visible una clara diferenciación de espacios ${ }^{36}$. La segregación en barrios emanaba de la propia trama urbana, donde se diferenciaba un casco histórico con calles estrechas, empinadas y tortuosas, de otras zonas ubicadas a las afueras de las antiguas murallas que, aunque con algunas ondulaciones propias de la orografía, representaban espacios algo más abiertos y zonas industriales, donde se situaban cines, paseos, el campo de fútbol, la plaza de toros, molinos y fábricas, así como las residencias de las clases populares. Principalmente, los barrios de extramuros, los de San Francisco y Barrio Bajo, eran habitados por los vecinos menos pudientes. Correspondían a las zonas exteriores de las secciones $2^{\mathrm{a}}, 3^{\mathrm{a}}$, $4^{\mathrm{a}}, 6^{\mathrm{a}}$ y $7^{\mathrm{a}}$.

Mapa 11: Distribución espacial de los jornaleros en el Arcos urbano

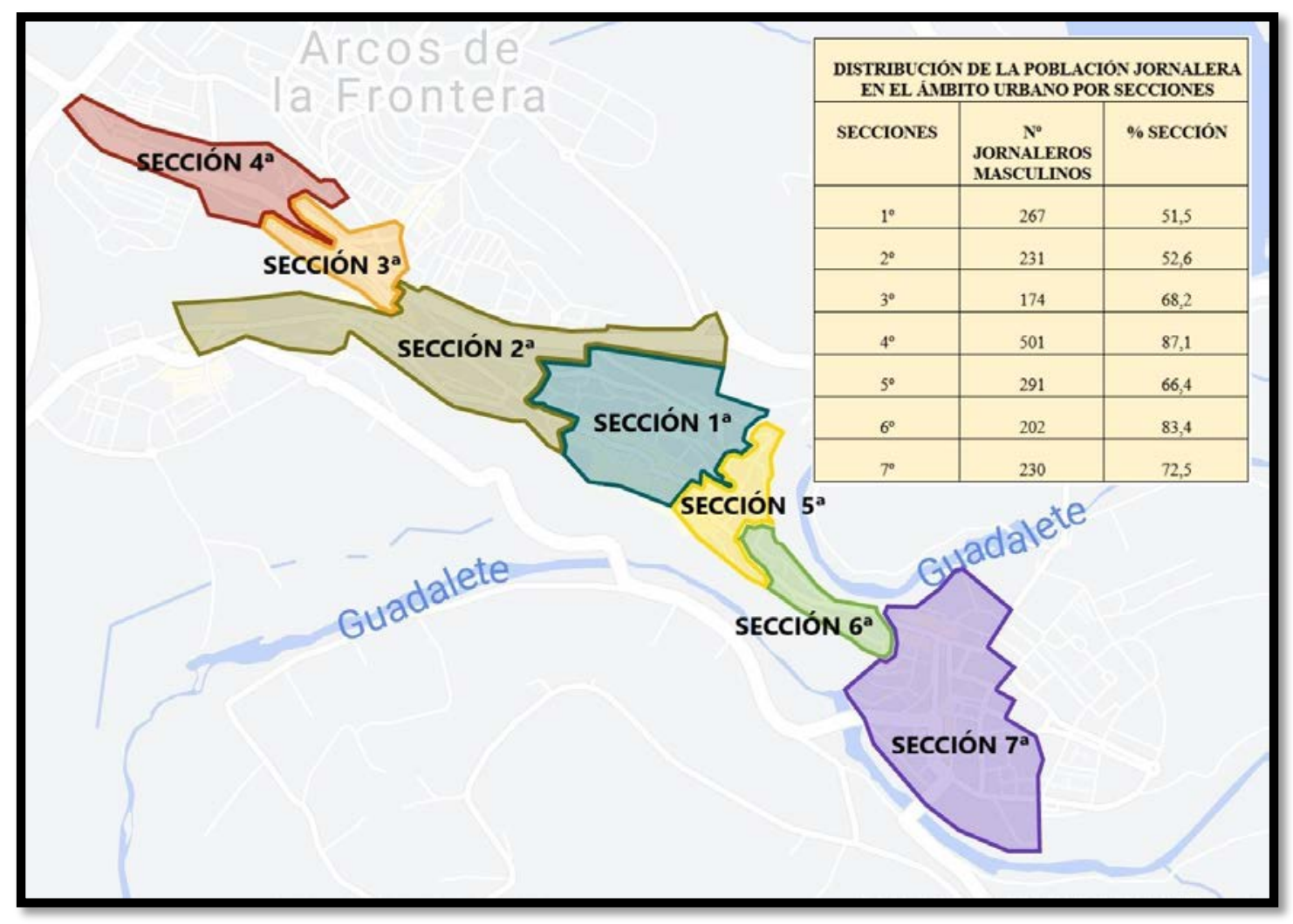

F.: elaboración propia con los datos del padrón vecinal de 1917 y las herramientas cartográficas de Google My Maps.

En 1920, Alfonso XIII apartó por decreto del poder local a los republicanos y otorgó la alcaldía a Juan José Velázquez-Gaztelu. También José Olivares ganó a finales de año la segunda acta de concejal por el tercer distrito, en unas elecciones municipales con escasa participación: solo un 40 por ciento aproximado de votantes. Poco después, en 1922, el joven conservador gobernaría la ciudad como primera autoridad ${ }^{37}$. La dictadura de Primo de Rivera detuvo su trayectoria política; se dedicó a su negocio y a ofrecer conferencias. En una de ellas expresó una representación de Arcos según su cosmovisión. A sus treinta y cuatro años describía a una agrociudad que había

36. BARRERA, “Perspectivas antropológicas”, p. 335.

37. AHMAF, Sig. 109, AC, 1-IV-1920, p. 34; El Guadalete, 24-2-1922, p. 1. 
interiorizado de forma sensorial. Arcos era "la de sonoras campanas" que con su "timbre” rememoraban sus días de fiesta y juventud o "con los lúgubres tañidos de sus dobles" traían a su memoria las desgracias, el anuncio de pérdidas de seres queridos que también se identificaba con "blancos mármoles de tu elevado cementerio". El espacio era concebido y halagado por ser antiguo y asociado a familiares y conocidos, la de "vetustos muros [que] cobijan seres tan queridos". Ciudad de las "blancas casas" y dependiente de "fértiles y pintorescos campos". Un lugar que despertaba admiración por ser una "bella e histórica ciudad". Un espacio habitado por "recatadas mujeres y nobles varones" ${ }^{38}$.

En sus descripciones de la Andalucía trágica, también Azorín plasmó una imagen de la agrociudad gaditana en la que destacó la actuación medioambiental de la Naturaleza en el paisaje de Arcos:

imaginad la meseta plana, angosta, larga, que sube, que baja, que ondula, de una montaña; poned sobre ellas casitas blancas y vetustos caserones negruzcos; haced que uno y otro flanco del monte se hallen rectamente cortados a pico, como un murallón eminente; colocad al pie de esta muralla un río callado, lento, de aguas terrosas, que lame la piedra amarillenta, que la va socavando poco a poco, insidiosamente, y que se aleja, hecha su obra destructora, por la campiña adelante en pronunciados serpenteos, entre terrenos y lomas verdes, ornado de gavanzos en flor y de mantos de matricarias gualdas... Y cuando hayáis imaginado todo esto, entonces tendréis una pálida imagen de lo que es $\operatorname{Arcos}^{39}$.

Esta pervivencia y vínculo con la naturaleza sigue presente en la descripción del periodista Enrique Garro, que añadía una semántica metafísica. Pero no solo eso, en su representación podemos observar un significado positivo de la Naturaleza y de la importancia histórica de la ciudad:

se proyectaría en el lienzo del cinematógrafo una película con vistas de Arcos de la Frontera, y la concurrencia creería estar presenciando desfiles panorámicos de poblaciones del extranjero que nos describieron ideales cuentos infantiles, [...] evoca al admirarla desde lejos los recuerdos de esas ciudades que, poseídas de un don sobrenatural, guardadora a su vez de tesoros inapreciables del arte antiguo [...] que son relicario de virtudes y civismo como elegidas por dios, que para tenerla más cerca ha elevado su nivel [...] el panorama es deliciosamente encantador; se transporta uno a otra región más pura, pues se ve la carretera, las personas, las casas como insignificantes juguetes hechos de cartón, que duran el tiempo que el niño tarda en disfrutarlos, mientras que la peña que nos sostiene se conservará firme, combatida por los tiempos, que no podrán más que su fuerte solidez. Domina allí la idea de grandeza, y no pasa por nadie el vértigo suicida, porque allá arriba piensa uno mucho más que en el llano en la obra de dios ${ }^{40}$.

Años antes, en la representación que realizó Manuel de Llano y Persi, podemos destacar la concepción del espacio como ecosistema humano, de paisaje en el que se fusiona lo humano y lo natural como algo mágico:

\begin{abstract}
la construcción o situación de las casas sobre todo es lo que más asombra: hay edificios que parecen imitar las diversas actitudes de Terpsícore, y no es muy raro ver que pace ganado encima de la techumbre de algo de ellos. Si el diablo en un momento de buen humor, hubiera querido meterse a arquitecto, de seguro no habría construido una población tan caprichosa y fantástica. Aquello asemeja tan solo una ciudad de naipes
\end{abstract}

38. Conferencia dada por D. José Olivares Piña sobre el tema Mejoras Locales en el teatro Olivares Veas de Arcos de la Frontera el día 8 de marzo de 1924, Arcos, Tipografía Arcobricense, 1924.

39. El Imparcial, 24-4-1905, p. 1.

40. ABC, Madrid, 16-12-1922, p. 6.

Rubrica Contemporanea, vol. X, n. 19, 2021. 
tirados a la ventura sobre la peña en que se sostienen sin duda por arte de mágica [sic] o como anomalía sublime en su género ${ }^{41}$.

Pero si esta representación oficial se realizaba desde las clases acomodadas o de quien plasmaba en la prensa nacional su descripción subjetiva del Arcos de principios de siglo XX, Miguel Pérez Cordón, figura reconocida en el anarcosindicalismo comarcal, destacaba la antigüedad de un espacio conflictivo ${ }^{42}$. A ojos del libertario del vecino pueblo de Paterna, que la pisaba en el otoño de 1932, las construcciones y edificios arcenses eran testigo del poder egoísta de lo religioso y lo feudal. Si destacaba "lo real que es la Naturaleza" en la propia ciudad, debido a su orografía y a las vistas de inmensos campos, la asemejaba al trabajo y a la vida como "tríptico de exuberancias múltiples mostrado ante nuestra mirada, ávida de ensoñaciones futuras”. Arcos tenía "características naturales para ser de las que figuren en los ensayos de un nuevo régimen social”. Se refería, sin duda, a una nueva representación sensorial del espacio urbano desde el comunismo libertario:

\begin{abstract}
al volvernos atrás y mostrársenos fría, acusadora, relatadora de la realidad del pasado, sintetiza en las vetustas construcciones, en las típicas callejuelas, en ese olor a incienso y a cera, a romances y comadreos, a hipocresía y solapadas envidias [...] ¿Guardarán los hombres en sus fibras sensoriales tradiciones añejas, arcaicas, aún? ¿Irán progresando al compás de estas ruinosas construcciones, símbolos mudos de un pasado de odios y crímenes inquisitorial y bárbaro? ${ }^{43}$.
\end{abstract}

También era una ciudad concebida como sujeto o entidad maltratada. Si desempeñaba una función de capitalidad subprovincial para los pueblos cercanos al dar nombre y ser cabeza del partido judicial, este papel acarreaba pesadas obligaciones, como el mantenimiento del Juzgado o de la cárcel del partido de Arcos de la Frontera. Esta responsabilidad históricamente también ofreció cierto prestigio a conciencia de algunos de sus moradores. Por eso, cuando se produjeron las distintas ordenaciones del territorio español a lo largo del siglo XIX, con sus continuos cambios a nivel electoral, judicial y sobre todo impositivo, se dieron conflictos entre los espacios, que son todavía constatables en la primera mitad del siglo $\mathrm{XX}^{44}$.

En este sentido, es palpable la identificación localista y el orgullo en las apreciaciones de sus moradores. La ciudad, desde una visión conflictiva entre las localidades de la provincia, era denominada como "la Cenicienta" ${ }^{45}$. Decía Olivares Piña que Arcos "parecía erguirse en son de protesta del lamentable abandono y atraso en que se encuentra sumido este precioso y feraz rincón de la Serranía”. Su tío, el notario Miguel Mancheño, también se había referido a ella como una urbe decadente, atrasada y olvidada. Sustentaba esta idea en la pérdida de autonomía de la localidad y, sobre todo, de sus fondos económicos, que podrían, según el notario, invertirse en mejorar necesidades perentorias para el desarrollo de la población, como el caso de las comunicaciones. La Diputación Provincial se percibía como "inútil ruedo de mecanismo gubernamental” que no invertía en esta ciudad "una parte siquiera de las enormes

\title{
41. Gente Vieja, 30-3-1902, p. 4.
}

42. Sobre Miguel Pérez Cordón, José Luis GutiÉRrez MolinA, Casas Viejas: del crimen a la esperanza. María Silva 'Libertaria’ y Miguel Pérez Cordón, Córdoba, Almuzara, 2008.

43. La Voz del Campesino, 29-10-1932, p. 2.

44. Otro ejemplo son las distintas luchas emprendidas en diferentes años por lograr la pervivencia de un colegio de Segunda Enseñanza (HMAF, Sig.119, AC, 7-7-1933, p. 9; 14-7-1933, p. 18).

45. Miguel MancheÑo, Revista Grandes Fiestas, Arcos, Tipografía Arcobricense, 1922. 
cantidades que por contingente provincial de Arcos percibe” ${ }^{46}$. Así, y aunque quizás el caso más paradigmático sería el de la ciudad de Jerez, los arcenses también vieron como un lastre su dependencia de la Diputación Provincial de Cádiz ${ }^{47}$.

Como en otras localidades. esas tensiones entre espacios también se dieron entre los propios barrios de Arcos, como deja de entrever la lucha de los vecinos de San Francisco, del Barrio Bajo y de Jédula para que se construyan escuelas en sus distritos en vez de en otros $^{48}$.

Mapa 10: Partido judicial de Arcos de la Frontera y tensiones entre la capital de provincia y agrociudades subprovinciales

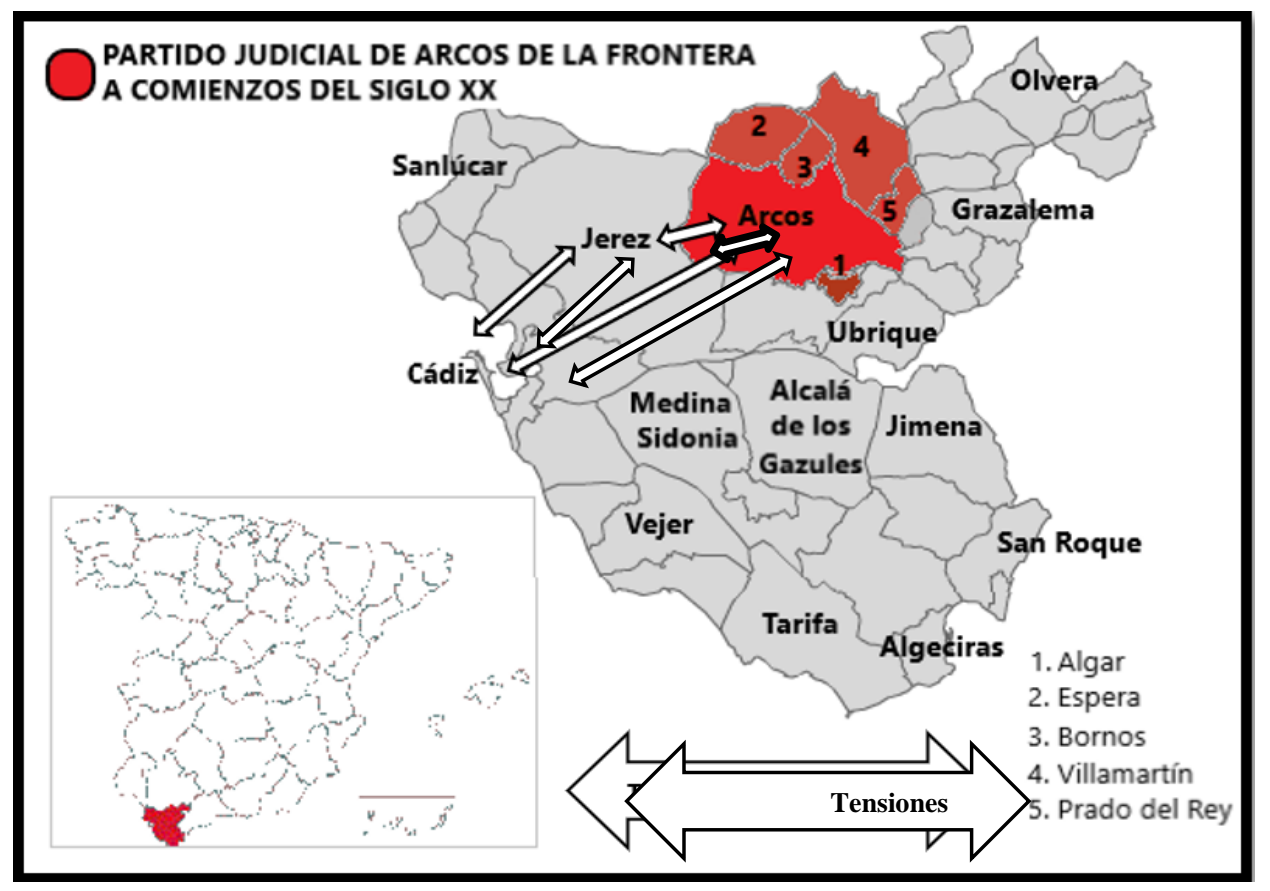

F.: elaboración propia.

En 1924, José Olivares Piña explicaba en su conferencia que los cambios que necesitaba la ciudad comprendían la limpieza pública, el alcantarillado, el abastecimiento de aguas y la construcción de casas baratas para los obreros, dando muestra de una semántica urbanita del espacio. En retrospectiva, se trataba de la revolución higienista de principios de siglo y la concepción de éste como salubre y sensorial. Entre sus propuestas estaban la creación de contenedores de hierro o de madera con zinc, de forma que se ordenase el espacio para evitar el mal olor y las "perniciosas consecuencias de su constante fermentación al pie de las viviendas"; también la construcción de más alcantarillas y la preocupación por el embellecimiento de las calles mediante la ampliación del presupuesto para aceras y empedrados bajo el

46. MANCHEÑO, Apuntes para una historia, pp. 37-38.

47. Los reclamos de impuestos y las disconformidades en las cantidades asignadas en las rentas provinciales serán motivo de debate público e, incluso, impulsarán candidaturas políticas (El Arcobricense, 30-1-1909, p. 1; 15-2-1909, p. 1; El Eco de Arcos, 11-8-1912, p. 1).

48. AHMAF, AC, Sig. 120, AC, 15-11-1935, p. 79. Antonio ORTEGA CASTILLO, "Las políticas educativas en el Arcos de la Segunda República. De la creación de escuelas al museo circulante de las Misiones Pedagógicas (1931-1934)”, en Santiago MoRENo y Ángel QUINTANA (coords.), Estado, educación y poder. El sistema educativo de la Restauración borbónica al primer franquismo en la provincia de Cádiz, Cádiz, Ubisunt?, 2018, pp. 91-134. 
que tendría que llegar el agua corriente en dos formas: fuentes públicas y suministros privados, abonados mediante contadores para las familias pudientes ${ }^{49}$.

También comentaba el empresario harinero que la "higiene material está[ba] íntimamente ligada con la higiene moral”. Por eso, y utilizando un llamativo carácter localista y asociándolo al ethos urbano, hablaba de que la "higiene moral" se obtenía educando para que "un arcense, donde la honradez y rudeza del trabajo se disputase el primer puesto, le viésemos triunfar". Sin embargo, la higiene material no se daba en una ciudad masificada. Los barrios obreros eran los más densamente poblados. Por ejemplo, la calle San Francisco -sección $4^{\mathrm{a}}$-, en el antiguo convento, los números 17 y 18 se encontraban abarrotados. En el primero habitaban 12 familias en 14 cuartos y en el segundo, 51 familias en 65 habitaciones. Aún peor era en la calle Magdalena Amaya número 1, en pleno casco histórico, donde 22 familias ocupaban una habitación cada una. En el mismo sentido estaba dispuesta la habitabilidad en todas las calles; resaltaban los casos de la finca situada en el número 18 de la calle Maldonado, donde había censadas 10 familias para 11 cuartos, o de la calle Torre Esquina 12, en la que 10 familias habitaban un cuarto cada una ${ }^{50}$. Sobre estas zonas de la agrociudad, Olivares Piña comentaba:

\begin{abstract}
El problema de la vivienda en Arcos reclama pronto remedio, rápida solución, para que esos seres, desheredados de la fortuna, siquiera puedan disfrutar de las caricias de los suyos en habitaciones higiénicas y holgadas de sus modestas viviendas, y que los ratos de descanso en la lucha por la vida no les sirvan de nuevo de tormento al verse hacinados como cerdos de pocilga ${ }^{51}$.
\end{abstract}

A finales de 1930, 11.027 personas habitaban el espacio urbano en un total de 1.163 edificios dedicados a vivienda, más 24 albergues y 68 construcciones dedicadas a otros usos. En su mayoría, los edificios solían ser de dos pisos (856 de ellos) ${ }^{52}$. Solo dos edificios tenían cuatro plantas; 45, tres y 328, un solo piso. Este hacinamiento y las pocas posibilidades de la orografía hacían que las condiciones salubres fuesen deficientes. En 1909, los vecinos de la calle Maldonado se quejaban de que la zona de la peña era un "lodazal inmundo de basuras y demás excrementos" 53 . En 1932, la Guardia Municipal del distrito de San Francisco, denunciaba el "estado deplorable" en el que se encontraba el "vacíe situado junto al Exconvento" ${ }^{4}$.

Sin embargo, por su esencia pintoresca y árabe, es decir, por su patrimonio histórico-artístico, las calles y casas arcenses fueron protagonistas de reportajes en la prensa nacional ${ }^{55}$. En muchos casos se trataba de antiguas casas palacio, ahora dadas en alquiler a varias familias. Frente a estas casas compartidas, encontramos los hogares de la burguesía local: allí erigieron sus casas en las calles Sagasta y Castelar, entre otras,

49. AFMPR, Conferencia de D. José Olivares Piña.

50. AHMAF, Sig.1.652, Exp. Confección 1930-1931.

51. AFMPR, Conferencia de D. José Olivares Piña

52. AHMAF, Sig.1.652, Exp. Instruido para llevar a efecto el Censo de población de 1931.

53. El Arcense, 10-4-1909, p. 1.

54. AHMAF, Sig.1.652, Exp. 46, Oficio de la Inspección de Policía Urbana y Rural, 1932.

55. Mundo Gráfico, 21-7-1915, p. 20. 
las familias Moreno, Reyes o Zapata, junto a sedes como la Banca Prieto o el Círculo Cultural Miguel Mancheño ${ }^{56}$.

Las casas de extramuros, que repetían la estructura y morfología del casco histórico, solían ser de dos plantas, construidas en torno a un patio central con habitaciones, cada una de las cuales ocupaba una familia, que así disponía de verdaderos espacios para la sociabilidad informal. Eran en estos espacios, en la esfera privada, donde la mujer cobraba su máximo protagonismo. En esta casa compartida solía existir un patio donde había un pozo, un lugar para preparar la comida a modo de cocina y, en el mejor de los casos, un corral donde criar algunos animales (gallinas, pollos o cerdos). Por supuesto, la habitación ocupada no era propiedad de la familia y se pagaba una renta mensual. En esta casa de vecinos discurría la mayor parte del tiempo de la mujer de familia obrera, que establecía lazos de solidaridad y sociabilidad entre sus vecinas. Era la encargada de mantener el duelo a los seres queridos fallecidos y de anhelar su recuerdo, como depositaria de la memoria familiar ${ }^{57}$.

Este patrón tradicional en los roles de género entraría en conflicto con la aparición de nuevas corrientes de comportamiento. Enrique Gamaza se refería al travestismo y a la libertad de sexo y género, que comenzaba a darse sobre todo en las grandes urbes como uno de "los caprichos virulentos del modernismo". Según este vecino de Arcos, se trataba de una "feminidad masculinizada o viceversa" que denigraba las "formas femeninas" porque las mujeres consumían tabaco, alcohol y otras drogas. No quedaba mejor parado el sexo masculino, pues en una comparación entre el hombre del siglo XIX y el "semihombre del siglo XX", este último era un ser "deteriorado, ridículo e incompleto" y "vergonzoso ejemplar, enfermizo y débil" además de "grotesco" por tener orientaciones homosexuales ${ }^{58}$.

Con el nuevo siglo surgieron nuevas prácticas sociales que modificaron la cotidianidad. En los años diez del siglo XX está totalmente implantado el ocio y con él el fútbol como un deporte de masas. Pero si en este espacio se recibieron de buena manera muchas de las nuevas formas de sociabilidad y ocio, también se mostraron apáticos y resistentes frente a otras como el cinematógrafo. En 1918, Alberto Risco denunciaba los graves perjuicios que ocasionaba el cine mediante la historia de un pequeño que quedó supuestamente herido por la visión de una película. El cine era un elemento perturbador de la moral y además podía ocasionar lesiones corporales. El articulista recomendaba:

¡cuántos y cuántos hijos de buenas madres habrán salido del cine con más que lesiones en el corazón, porque han salido con el alma muerta y la inocencia asesinada! ¡Cine, de cualquier clase que seas, seas mil veces maldito! ${ }^{59}$.

No eran las únicas prácticas sociales mal vistas en el Arcos de comienzos de siglo XX. Los grupos acomodados y las personas más cercanas a la élite de la cultura local percibían a las clases populares como seres manipulables y de baja moralidad. Es una visión presente en los escritos de Miguel Mancheño para fines del siglo XIX y que

56. La habitabilidad en Manuel PÉRez Regordán, La historia de Arcos a través de sus calles, Arcos, Ayuntamiento de Arcos, 2002.

57. Hemos podido acceder al papel relegado a las mujeres en la primera mitad del siglo XX a través de las entrevistas que hemos realizado a las vecinas: Antonia Rodríguez Oca (3-8-2015), Isabel del Valle (17-82015), Adela Oliva Borrego (15-2-2016) y Cristobalina Álvarez Carles (10-8-2015).

58. El Eco de Arcos, 9-12-1928, p. 2.

59. El Eco de Arcos, 20-1-1918, p. 3.

Rubrica Contemporanea, vol. X, n. 19, 2021. 
continúa en los años veinte del siglo siguiente en el pensamiento de esta elite, como bien deja de entrever la conferencia ofrecida por otro de sus sobrinos, Manuel Martín de Mora y Meléndez, también alcalde y diputado provincial en dicha década. Destacaba la supuesta inclinación proletaria por frecuentar la taberna, donde practicaban el juego y el vicio. Decía que los patronos veían "constantemente" a los obreros en "las tabernas bebiendo vino, aun de las más costosas marcas [...], jugar a los prohibidos el importe de vuestros jornales; observan en vuestras familias un lujo exagerado e innecesario”. Según el abogado, las jóvenes de familias obreras "no por vestir con sedas, gasas y perifollos" iban a ser "más respetadas que lo eran, cuando iban limpias, airosas y modestas, conforme a su clase y condición”. Así, según Mora, el obrero quería un aumento de jornal "para malgastarlo en vicios" y en "degradarse más aún” 60 .

En cambio, los jornaleros organizados culpaban al latifundismo de su desgracia. Esta organización y propiedad del espacio los habían "sumido en la miseria", que se agravaba "a causa del progreso de la mecánica en la agricultura”. Es decir, la propiedad en pocas manos y el empleo de máquinas que traían la modernización agraria habían dejado "a toda la región agrícola en la más desoladora ruina”. Sin embargo, también desde la prensa local se asociaba la pobreza jornalera con el lumpen y el vicio ${ }^{61}$.

Había una lectura fatalista y desgraciada de quien visitaba las tabernas. Estas constituían un lugar lúdico, cotidiano e informal en el que confluían, generalmente, hombres para beber, relacionarse y jugar a las cartas ${ }^{62}$. Otros lugares de sociabilidad que se diferenciaban de las tabernas fueron los casinos o los cafés, muchos de ellos con origen en una asociación gremial, ideológica o cultural. Al menos desde el siglo XIX, se conocían estos espacios de sociabilidad en Arcos, donde existían cinco casinos. José Olivares Piña sería el vicepresidente de los dos más importantes. Desde joven fue secretario -más tarde vicepresidente y presidente- del Círculo La Unión, el de más pedigrí, el más antiguo -de 1841- y el que poseía el teatro que se denominaría Olivares Veas en honor a su padre ${ }^{63}$. Se trataba de un lugar de paso obligado para los habitantes acomodados cuando estaban en la ciudad para cerrar acuerdos económicos, confeccionar listas electorales, celebrar banquetes y recibir a las autoridades o visitantes reconocidos. También se organizaban bailes, a los que asistían las familias pudientes, actividades que organizaban los "socios de tan culta sociedad" 64 .

Pero si hay puntos de desencuentro entre los habitantes de la agrociudad, también los hay de encuentro. Solían identificarse con el sentimiento localista, ya tratado, pero también con el espiritual o sagrado que, en muchos casos, representaban las hermandades religiosas o las celebraciones del día de los patronos o de la feria de

60. Conferencia de Manuel Martín de Mora «El Obrero Íntimo» con fecha de 27 de febrero de 1920, Arcos, Tipografía Arcobricense, 1920.

61. AHMAF, Sig.45, Sociedad Fraternidad Obrera 1930. En esos términos se expresaba el periodista Ricardo Naranjo recreando la historia de un supuesto agricultor endeudado por el juego: El Eco de Arcos, 6-1-1918, pp. 2-3.

62. Se trata de un espacio en el que confluyen dos rasgos básicos de lo que se conoce como "sociabilidad informal”: voluntariedad y "no interferencia de otras instancias sociales” (Jorge URÍA GONZÁLEZ, "La taberna. Un espacio multifuncional de sociabilidad popular en la Restauración española”, Hispania, 214 (2003), pp. 571-604 (https://doi.org/10.3989/hispania.2003.v63.i214.225).

63 El Guadalete, 5-1-1923, p. 1; 24-2-1915, p. 1.

64. Un ejemplo en El Arcense, 10-4-1909, p. 3. 
ganados ${ }^{65}$. Esta última, era un tiempo y un espacio clave, como referencia cosmológica y polo de atracción de la vida en el campo, de lo rural y de las nuevas innovaciones tecnológicas procedentes, en su mayoría, del mundo urbano ${ }^{66}$. Se diferenciaba del mercado local que diariamente funcionaba en las plazas de abastos, a las que los vendedores, muchos procedentes del mundo rural de los alrededores, tendrían que acceder tras abonar los arbitrios en pequeñas casetas situadas en puntos estratégicos a la entrada de la ciudad.

Si el mercado constituyó un lugar de encuentro entre campo y ciudad, el espacio clave donde se van a mostrar las tensiones y las representaciones sociales más conflictivas será la plaza del Ayuntamiento. Era el corazón de la agrociudad. Se trata del lugar donde se sitúan los poderes civiles (Casa Capitular y oficina de la Guardia Municipal con la cárcel) y religioso o espiritual (la iglesia Mayor de Santa María). En la plaza se realizarán las exposiciones de distintas creencias políticas, tanto oficiales como extraoficiales, con especial importancia de la concentración de obreros para demandar faenas agrícolas, cambios políticos o socorros. Este lugar es a su vez donde confluyen distintas representaciones de la realidad y las preocupaciones subyacentes al mundo rural (reparto de tierras, producción, trabajo...) y el urbano, del que emana el poder transferido desde la capital de provincia y personificado en la figura del gobernador civil $^{67}$.

En este sentido, si hay que destacar un elemento básico para poder percibir el lugar de encuentro que significa Arcos entre el espacio agrícola y rural que comprende sus alrededores y su núcleo urbano, ése es el fenómeno histórico de la politización y la sindicalización. En un diálogo continuo entre condiciones rurales y urbanas, los vecinos adoptaran los grandes movimientos ideológicos como instrumentos para la mejora de las condiciones de vida de las clases populares. La fecha clave es el año 1931 por dos razones: porque, en un movimiento mimético a lo que acontecía en la esfera nacional, verdaderamente se logra quebrar las agrupaciones políticas de los oligarcas locales y se da una proliferación, hasta entonces desconocida, de partidos políticos republicanos y sindicatos. Éstos recogían las aspiraciones de una clase media urbana y otra obrera, y que claramente son movimientos importados de otras localidades como Jerez o Cádiz.

En segundo lugar, es en 1931 cuando la mayor organización sindical de la ciudad, Sociedad Fraternidad Obrera, se adhirió a la CNT-AIT, un movimiento de masas que, si en lugares como Cataluña o Madrid era netamente urbano y ligado a trabajadores industriales, en la Baja Andalucía tendría un componente claramente campesino y colectivista ${ }^{68}$. Gracias a los aires de libertad y a las nuevas ideas, tras su resurgimiento en 1930, Fraternidad Obrera en apenas unos meses se convertirá en la asociación obrera más potente que había tenido la localidad, agrupó a varios gremios y, como había hecho en décadas anteriores, recogió las demandas sociales de los jornaleros, pero incorporando el fenómeno de masas que significa el anarcosindicalismo

65. Puede verse como caso El Eco de Arcos, 20-4-1930, p. 2.

66. Antonio Ortega Castillo, "La feria de San Miguel: un punto de referencia en el calendario de los arcenses”, Revista de feria de Arcos, Publicaciones del Sur (18 septiembre 2016), pp. 22-23.

67. Algunos ejemplos de estas representaciones del conflicto en la plaza: El Guadalete, 19-2-1907, p. 2; 25-2 -1936, p.3; La Correspondencia de España, 2-4-1907, p. 3.

68. El anarquismo en la comarca en José Luis GUTIÉRREZ MOLINA, La idea revolucionaria. El anarquismo organizado en Andalucía y Cádiz durante los años treinta, Fuenlabrada, Madre Tierra, 1993; Jacques MAURICE, El anarquismo andaluz, Barcelona, Crítica, 1989. 
español de los años treinta. Ello valdrá para lograr numerosas conquistas en las condiciones de trabajo en el espacio agrícola y, por extensión, en el rural, donde van a comenzar a emerger filiales obreras de las asociaciones de Arcos ciudad ${ }^{69}$. Incluso, basado en el ideario anarquista, se proclamará el comunismo libertario como alternativa al modelo político, social, económico y cultural, una alternativa que se intentó convertir en realidad y que partía de postulados razonados y pragmáticos, ya que la estructura productiva y el contexto de los años treinta, como hemos visto en el epígrafe anterior, eran propicios para sus aspiraciones ${ }^{70}$. Un ejemplo de esto que decimos fueron prácticas sindicales que promovieron las huelgas revolucionarias, la idea de acción directa o el rechazo a la legislación laboral republicana. Es lo que ocurre en Arcos en los años treinta, y concretamente en enero de 1933, cuando los campesinos anarcosindicalistas recorren los campos con armas y ocasionan incidentes en la ciudad, como se hizo en otras agrociudades: Jerez, Medina Sidonia, Sanlúcar, así como Casas-Viejas, la vecina aldea de triste recuerdo ${ }^{71}$.

\section{A modo de conclusión: agrociudades como fronteras de las representaciones urbanas y rurales}

Arcos constituye un caso paradigmático de lo que se conoce como agrociudad. Al ponerlo como ejemplo, en este artículo hemos intentado señalar la relevancia de estos lugares, nada escasos en el territorio peninsular, que constituyen espacios de encuentros y desencuentros entre distintas concepciones y representaciones del espacio.

No es posible comprender la historia de España en la etapa contemporánea sin tener en cuenta a espacios de transición entre el mundo urbano y el rural. La agrociudad probablemente sea el mejor concepto que tengamos hoy día para definirlos y por ello es interesante que se convierta en objeto de estudio principal de las investigaciones históricas, tome entidad propia y deje de ser una mera contextualización productiva en trabajos que se centran en otras cuestiones. Es importante que, como hemos intentado demostrar en este artículo, la lectura netamente productiva del concepto de agrociudad derive hacia lo que nos vienen indicando desde hace varias décadas otras ciencias sociales: un espacio vivido, representado y conflictivo con rasgos de urbanidad y en el que sus habitantes son portadores de lo que se conoce como ethos urbano. También hay que considerarlas como un espacio semántico con distintas agencias y, por supuesto, experiencias que conforman visiones totalmente contrapuestas. Para ello, una herramienta especialmente beneficiosa es el uso de cartografía personalizada donde proyectemos esas representaciones para ampliar nuestra visión y consolidar así, también en la historia contemporánea, la cartografía como parte integral del método científico.

Por último, es necesario recalcar que a la caracterización que hasta ahora se ha realizado de la agrociudad desde distintas ciencias sociales, sería interesante añadir su importancia como espacio para la consolidación de la modernización del país a comienzos del siglo XX, con especial atención a la popularización de nuevas ideologías,

69. Es el caso de Jédula, AHMAF, Sig.1.012, Fraternidad y Progreso. Sobre el movimiento de masas cenetista, Julián CASANOVA RuIZ, De la calle al frente. El anarcosindicalismo en España, Barcelona, Crítica, 2010; ídem, Tierra y Libertad. Cien años de anarquismo en España, Barcelona, Crítica, 2011.

70. La idea de pragmatismo y razonamiento ha sido expuesta últimamente en Julián VADILLO MUÑOZ, Historia de la CNT. Utopía, pragmatismo y revolución, Madrid, Catarata, 2019.

71. ORTEGA, “Conflictividad en la campiña”, pp. 221-234.

Rubrica Contemporanea, vol. X, n. 19, 2021. 
ORTEGA

que democratizaron el sistema político español y que mermaron el régimen oligárquico. Desde la Historia, habría, por tanto, que profundizar en estos espacios, que funcionan como ejes conectores entre lo urbano y lo rural; en las agrociudades, que desarrollaron el rol de representante del mundo rural y a la vez como espacios delegados del poder residente en las grandes ciudades y capitales, escenarios de innovaciones políticas, sociales o tecnológicas y al mismo tiempo depositarios de la tradición. 